\title{
EL OBISPO PEDRO CIRILO ÚRIZ Y LABAYRU EN LA ENCRUCIJADA DEL CONCORDATO DE $1851^{1}$
}

\author{
POR \\ Francesc Closa Salinas \\ Universidad de Lleida
}

\section{RESUMEN}

En los albores de 1851, fecha de aprobación del Concordato entre el gobierno español y la Santa Sede, Úriz es preconizado como obispo de Lleida. Tiene ante sí una difícil tarea, modernizar un obispado duramente castigado por las guerras y la ausencia -durante varios años- de un pastor eclesiástico. Úriz se nos presenta como un enérgico prelado artífice de la reordenación, modernización y actualización del obispado según los preceptos concordatorios. Este minucioso trabajo irá acompañado de una reflexión sobre el papel de la iglesia ante los enormes cambios que tomaba el país. En sus pastorales imputa a los liberales la causa de la gran tragedia de la iglesia en España. Ante ello propone que el catolicismo se convierta en una verdadera religión oficial y que volviera a disfrutar de algunos de sus tradicionales privilegios, perdidos durante la primera parte del siglo XIX. A cambio aceptarían la monarquía isabelina, el gobierno moderado así como la modernización y cambios en el campo social, tecnológico e incluso cultural del país.

Palabras ClaVe: Obispo Úriz, obispado, Lleida, Concordato 1851.

\section{PEDRO CIRILO ÚRIZ Y LABAYRU BISHOP IN THE CROSSING OF THE CONCORDATO OF 1851}

\begin{abstract}
At the beginning of 1851, when the Concordat between the Spanish Government and the Holy See was signed, Úriz was advocated Bishop of Lleida. He had to face a very difficult task: to modernize a bishopric harshly punished by
\end{abstract}

\footnotetext{
${ }^{1}$ Este artículo es la versión extendida de la conferencia realizada en Olite el 28 de mayo de 2010 (Navarra) en el marco de las jornadas dedicadas a D. Pedro Cirilo Úriz, obispo de Lérida (1850-1861) y de Pamplona (1861-1870). Quiero aprovechar la ocasión para agradecer todo el apoyo documental recibido de mi buen amigo Javier Corcín.
} 
wars and the absence -for many years- of a pastor. Úriz was presented as an energic prelate who was the architect of the reordination, modernization, and updating of the bishopric according to Concordat precepts. This thorough work would be accompanied with an arduous task of reflection about the Church's role when facing the huge changes which were taking place in our country. In his sermons, he accused the liberals of being the cause of the Spanish Church's great tragedy. He suggested turning Catholicism into an official religion so that it could enjoy some of its traditional privileges in exchange for the acceptance of the Isabelline monarchy, the moderate government and modernity in the social, technological and even cultural fields.

KEY WoRDS: Bishop Úriz, Lleida, Concordato 1851.

$\begin{array}{ll}\text { Recibido/Received } & 22-12-2010 \\ \text { Aceptado/Accepted } & 21-07-2014\end{array}$

\section{La llegada del obispo Pedro Cirilo Úriz y Labayru}

La llegada de un nuevo prelado al obispado de Lleida se convirtió en un hecho relativamente importante debido a una prolongada vacante, durante muchos años, de un pastor eclesiástico. ¿Quién era Pedro Cirilo Úriz y Labayru? Pasemos a describir someramente algunas de sus principales características biográficas con la pretensión de apreciar aquellos aspectos que conformarían su personalidad, forjarían los rasgos de su carácter, su conducta y su praxis ante los cambios estructurales acontecidos en la España post concordatoria.

Úriz nació el 9 de junio del año 1799 en la ciudad navarra de Olite. Sus padres, Luís Ventura Úriz y Juana Labayru, lo bautizaron dos días después en la parroquia de Sant Pedro Apóstol de la misma localidad navarra. ${ }^{2}$ Su vida siempre estuvo atada a la de su tío, Joaquín Xavier de Úriz y Lasaga, obispo de Pamplona, adalid de la causa realista que espoleado por el triunfo de las tendencias liberales abandonó España, hacia 1822, para volver al cabo de un año al frente de los cien mil hijos de San Luís.

Joaquín Xavier le introdujo en el Seminario Conciliar de la capital navarra para estudiar filosofía y teología. De él heredaría una valiosa biblioteca con más de un centenar de las mejores obras teológicas del siglo. Posteriormente

\footnotetext{
${ }^{2}$ Esta biografía se basa en las aportaciones realizadas por Goñi Gaztambide, Jose 1991. Historia de los obispos de Pamplona. Siglo XIX, vol. X, Pamplona: Ediciones Universidad de Navarra, especialmente páginas 12 a 21 . Esta obra es esencial para entender la tarea pastoral y organizativa realizada por el prelado en el obispado iruñense. De modo más genérico puede consultarse la macro obra España Sagrada, Tomo XLVII, Madrid, 1850, 150 y la obra de: Ibarra, J. 1953. Biografías de los ilustres navarros del siglo XIX y parte del XX, tomo IV: 376-379 Pamplona.
} 
pasaría a la Universidad Literaria de Huesca donde estudiaría derecho y, posteriormente, ocuparía el cargo de vicerrector. ${ }^{3}$ A los 17 años recibe la sacristía de la iglesia parroquial de San Pedro de Olite. ${ }^{4}$ Dos años después asciende a medio beneficio y deja la sacristía. Cuando tenía veinte años obtenía el pleno beneficio. El 1824 conseguía los grados en doctor en Derecho y fue ordenado sacerdote. Durante diez años ocupó la cátedra de derecho canónico en la Universidad de Huesca. ${ }^{5}$ También fue agraciado, previa oposición, con una beca de jurisprudencia canónica del colegio de San Vicente Mártir de Huesca. A lo largo de aquellos años ejerció de Provisor y Vicario General de la abadía de Montearagón. Posteriormente fue nombrado canónigo doctoral del obispado de Tarazona hacia 1833. Úriz siempre destacó por su lealtad al régimen monárquico, la defensa del clero nacional y la lucha contra el liberalismo más radical. La defensa de los derechos de la Iglesia y su negativa a reconocer como vicario capitular al obispo impuesto por el gobierno liberal a la mencionada diócesis de Tarazona le comportaron tres años de confinamiento en Jaca (1836-1939). Posteriormente, tuvo que emigrar a Francia. Retornó a Pamplona hacia 1840. A partir de entonces participó activamente en el Seminario Conciliar de la capital navarra mejorando su plan de estudios con la incorporación de nuevos métodos didácticos así como la dotación de gabinetes de física y ciencias naturales. Todo ello hacía predecir uno de los elementos que caracterizarían posteriormente el corpus teórico del prelado, su posicionamiento ante la catarsis sufrida en España y su enérgico trabajo en los obispados de Lleida y Pamplona.

\footnotetext{
${ }^{3}$ Gran parte de su biografía puede consultarse en el Boletín Eclesiástico Obispado de Lérida (a partir de este momento aparecerá con las siglas BEOL), núm. 122, 30 agosto 1870, 271-283; en los Anales de la Academia Bibliográfico Mariana, año VIII, Lérida, 1869; en el Arxiu Capitular de Lleida, caja 73 (2), Carpetas Biblioni: obispos de Lérida, carpeta 36: obispo Úriz; en el Boletín oficial eclesiástico del obispado de Pamplona, 16 julio 1870, 205-215 y en el documento Consagración del Ilmo. Sr. Don Pedro Cirilo Úriz y Labairu, obispo de Lérida, Libro 6 Bautizados 1843-1861 del Archivo de San Pedro de Olite.

${ }^{4}$ Presentó el memorial de la siguiente forma: «D. Pedro Cirilo Úriz y Labayru clérigo tonsurado y natural de esta ciudad dice: que por mejor servir a Dios en el estado eclesiástico se halla estudiando en la sagrada teología en el Seminario Conciliar de Pamplona y con el objeto de recibir las sagradas órdenes se ve precisado a recurrir a la piedad de usted a fin de que se digne adjudicarle la sacristía de la parroquia de Santa María que se halla vacante por desistimiento que hizo D. Martín Gómez respecto de ser el único tonsurado y habilitado de dicha ciudad para la obtención de la tal sacristía colativa y eclesiástica favor que espera de la benignidad de Vds. A Olite veintiséis de diciembre de mil ochocientos diecisiete. A nombre del suplicante y con su orden D. Pedro Labayru.

Recae el nombramiento en D. Pedro Cirilo Úriz por ser la persona en quien concurren las circunstancias debidas. En 1819 asciende a medio beneficio y deja la sacristía», Archivo de Santa Maria de Olite, Libro 34: Libro de providencias y autos, folio 102, 1817: Nombramiento de sacristán a favor de D. Pedro Cirilo Úriz y Labayru.

${ }^{5}$ Fue regente de la cátedra tercera de cánones (1824-1825), regente de Decretales (1825-1826), catedrático de Primera de Instituciones de Cánones (1826-1827) y finalmente catedrático de Decretales (1827-1833).
} 
A finales de los años cuarenta fue el enviado para dialogar con el Gobierno para evitar la supresión del capítulo y la diócesis de Tarazona en el concordato que se estaba negociando entre Madrid y el Vaticano. Consiguió que esta no fuera suprimida y favoreció, por el contrario, el nombramiento de un nuevo prelado, hecho que le supuso el reconocimiento de gran parte de la alta jerarquía eclesiástica española manifestado, por expresa orden de la reina, en su nombramiento como obispo de Lleida. ${ }^{6}$ Fue preconizado el 20 de mayo de 1850 y recibió la consagración episcopal de manos del obispo de Pamplona, Severo Andriani, asistido por los de Zamora y Tarazona. ${ }^{7}$ Enseguida inició la visita

\footnotetext{
${ }^{6}$ Archivo del Ministerio de Asuntos Exteriores (a partir de ahora AMAE), Santa Sede, Secretaría de Estado, legajo 722, núm. 182.

Esta misma noticia puede reseguirse en la carta que Úriz remitió al Ayuntamiento de Olite anunciando su elección como obispo de Lleida. Ello confirma la elección realizada por la reina probablemente como premio por su tenaz tarea al defender el obispado de Tarazona. Entre otras cosas decía Úriz: «Muy Señor mío: En un diario de Roma que leí ayer se anuncia que nuestro Santo Padre Pío Papa IX en el consistorio celebrado el 20 de mayo se dignó confirmar la presentación que S. Majestad La reina tuvo a bien hacer de mi persona para el obispado de Lérida. Aunque todavía no se he ha comunicado de oficio este acto me presumo a ponerlo en conocimiento de V. S. teniendo como tengo por cierta la noticia.

A cumplir con este deber me cabe la satisfacción de hacer saber a V. S, la suya mi intención de que el acto solemne de mi consagración se celebre en esta ciudad y parroquia de San Pedro, en que fui bautizado, y con presencia del ilustre Patronato a cuya bondad merecí el haber sido agraciado con la presentación de un medio beneficio y beneficio entero de cabildo eclesiástico de sus Parroquiales unidas, cuyas gracias tengo muy presentes en mi memoria para el agradecimiento. Creo que con el favor de Dios se realizará mi pensamiento, y a este fin me he puesto de acuerdo con los Ilmos. Señores Obispos de Pamplona, Tarazona y Zamora, preparado para cada una. Entre tanto y siempre espero que V.S. se servirá comunicarme las órdenes de su mayor agrado.

Dios nuestro Señor conserve a V. S. en su mayor lustre y esplendor por muchos años. Olite 7 de junio de 1850, firmado Pedro Cirilo de Úriz, Obispo electo de Lérida», Archivo Municipal de Olite, legajos, legajo 153, Resoluciones Ayuntamiento, Comunicación del obispo Úriz de su nombramiento en Lérida, 1850.

${ }^{7}$ Las celebraciones realizadas en Olite, su población natal, fueron importantes y alcanzaron gran trascendencia y eco: «En la ciudad de Olite a veintinueve de septiembre de mil ochocientos cincuenta, día en que Nuestra Madre la Iglesia celebra la dedicación de San Miguel Arcángel y dominica decimonona después de Pentecostés, se celebró en la iglesia parroquial de San Pedro Apóstol de la misma la consagración del Ilmo. Señor doctor don Pedro Cirilo Úriz y Labayru natural de esta ciudad y de la expresada parroquia de San Pedro, de la cual había sido beneficiado, canónigo doctoral que era últimamente de la iglesia catedral de Tarazona y obispo electo y preconizado como estaba para la ciudad y diócesis de Lérida en el Principado de Cataluña. Asistieron a éste solemne acto el Exmo. e Ilmo. señor doctor don Severo Andriani obispo de Pamplona, que fue el consagrante y celebró para ello de Pontifical, y los Ilmos. S.S. D. fray Vicente Ortiz y Labastida obispo de Tarazona, y don Miguel José de Irigoyen obispo de Zamora y preconizado para Calahorra era el designado para padrino don Pedro Labayru presbítero beneficiado jubilado de las parroquiales unidas de esta ciudad y tío carnal del señor obispo consagrado, pero ya fuese por indisposición o por su avanzada edad no asistió, e hizo sus veces y le sustituyó don Emeterio Úriz hermano del expresado señor obispo, natural y residente en esta ciudad. Un numeroso gentío se reunió se reunió para presenciar este religioso acto y es indecible al respecto la sumisión, el concierto y orden que se conservó por todas y cada clase de personas, a quienes lo majestuoso y tierno de la función causaba una grande emoción y júbilo. Esta función se
}

Hispania Sacra, LXVII

136, julio-diciembre 2015, 673-715 ISSN: 0018-215X, doi: 10.3989/hs.2015.020 
pastoral de su nueva diócesis. Su tarea al frente de la sede ilerdense fue enérgica y ardua aunque frenada en muchas ocasiones por los acontecimientos políticos del país. ${ }^{8}$ Úriz era consciente de la creciente pérdida de influencia de la iglesia sobre la sociedad.

$\mathrm{Su}$ actividad refleja la voluntad de conseguir poner orden entre los sacerdotes de un obispado largamente olvidado. De fondo había la necesidad de volver a influir sobre la estructura política local y los ciudadanos que en ella habitaban. ${ }^{9}$ Pretendía, por tanto, incrementar la influencia i la presencia pública de la Iglesia. En el presente artículo vamos a destacar cuatro de los ejes que van a marcar el obispado de Úriz; ${ }^{10}$ a) la reorganización interna del obispado. Por un

hizo vistosa con los repetidos obsequios que para ella tenía preparados el Ayuntamiento y Cabildo de esta ciudad: hubo fuegos artificiales bien ordenados por dos días consecutivos, que fueron los días veintiocho y veintinueve, asistiendo a ellos en el segundo los cuatro reberendos Prelados, cuyo carácter infundía en los fieles tal respeto, que no se oyó en el lugar donde se hallaban, que era en el balcón de la M. N. y M. L. ciudad palabra alguna descompuesta, al contrario, concluidos los fuegos se retiraron los S.S. obispos a sus casas acompañados del Ayuntamiento y Cabildo con las personas eclesiásticas de su servidumbre en medio de los vivas y aclamaciones de todos los fieles, que en el tránsito doblaban gustosos las rodillas para recibir las bendiciones de aquellos pastores, que quedaron muy satisfechos de tantos obsequios y sobre todo de las pruebas de respeto y religiosidad que se tributaron a sus dignidades. El día treinta se corrieron novillos en todo el día para aumento y colmo de los festejos hechos por tan fausto acontecimiento del cual se gloria esta ciudad por tener el honor de contar a uno de sus hijos en el número de los pontífices de la Iglesia. Se hicieron otros actos de alegría, de respeto en fin, acerca de los cuales podrán formar los venideros una idea propia de los sentimientos religiosos de un pueblo cristiano. Y para que conste firmo yo el infrascrito vicario de la parroquia de Santa María la Real de esta ciudad de Olite a primero de octubre de mil ochocientos cincuenta. D. Joaquín Jurío», Archivo de Santa Maria de Olite, Libro $-5^{\circ}$ bautizados, folio $-185 \mathrm{v}, 1850$ Advertencia para futura memoria. Consagración u ordenación de un obispo: don Pedro Cirilo Úriz.

${ }^{8}$ Relacionado con los avatares políticos y sociales en Lleida durante la década de los años cincuenta pueden consultar las siguientes obras: Casals Bergés, Quintí. 2002. Polítics de Lleida. El poder local i les seves mutacions a través del temps (1716-1868): Lleida: Diputació de Lleida; Casals Bergés, Quintí. 2001.»Absolutismo y revolución Liberal en Lleida (1715-1868). La lucha sociopolítica por la toma de la Paeria», La revolución liberal: (Congreso sobre la Revolución liberal española en su diversidad peninsular (e insular) y americana, Madrid, abril de 1999): 67-96; Jové, Antoni; Lladonosa, Manuel y Vicedo, Enric. 2003. Història de Lleida. El segle XIX: Lleida: Pagès editors; Pons Altés, Josep Maria. 1998. El poder polític a Lleida. 1843-1854. Eleccions i pronunciaments: Lleida: La Mañana; Pons Altés, Josep Maria. 2002. Moderats i progressites a la Lleida del segle XIX: Lleida: Pagès editors.

${ }^{9}$ Josep Maria Pons también ha puesto de manifiesto las nuevas estrategias movilizadoras llevadas a cabo por Úriz: Pons Altés, Josep Maria. 2005. «Església i política a la Lleida de mitjan segle XIX: reconciliació, legitimació i conflictes». Església, societat i poder a les terres de parla catalana. Actes del IV Congrés de la CCEPC: Barcelona: Institut Ramon Muntaner: 225-238.

${ }^{10}$ Hemos obviado por cuestión de espacio el intento del obispo de incrementar su capacidad supervisora sobre la enseñanza: Closa Salinas, F. Església i poder a la Lleida del segle XIX. Control i mobilització social: Pedro Cirilo Úriz y Labayru (1850-1861): Lleida: Servei de Publicacions de la Universitat de Lleida y también en el artículo Closa, Francesc. 2004. «L'estada del bisbe Pedro Cirilo Úriz y Labayru a Lleida (1850-1861): poder polític i mobilització católica. Analecta Sacra Tarraconensia 77: 381-412. 
lado intentó adecuar sus características religiosas y estructurales (demarcación, conversión de colegiatas en parroquias y arreglo parroquial) a las necesidades de la nueva coyuntura histórica. Por otro lado la modernización del Seminario Conciliar, abandonado desde tiempo atrás, y la reorganización del cementerio ambos obsoletos por el paso del tiempo y la ineficacia de algunos de sus predecesores. b) el redoblamiento de la vigilancia y control ideológico, moral y espiritual de un clero anclado en la desobediencia moral y personal. Ello le trajo consigo algunos duros episodios de enfrentamiento con el consistorio municipal de Lleida y con el gobierno de España, especialmente durante el Bienio. Su intención era continuar ejerciendo el control de la población civil. c) la creación del Boletín Eclesiástico del Obispado de Lérida, uno de los primeros de España, como método de difusión de sus prerrogativas y de reorientación de las actividades de los rectores de las parroquias del obispado. En último término, d) la reflexión teórica buscando el lugar que la Iglesia había de ocupar en el nuevo estado. ${ }^{11}$ Ello nos permite apreciar su particular visión de la religión ante los cambios sociales, políticos, económicos y religiosos que tomaba el país. Úriz se nos presenta, como observaremos más adelante, en un papel de legitimador político del régimen e incluso de mediador social. Todo ello tenía como trasfondo el intento de consolidación de la presencia pública de la religión católica y frenar los crecientes focos anticlericalismo, especialmente en las zonas más alejadas de Lleida.

Pasemos a continuación a analizar algunos de los principales campos de actuación y tareas llevadas a cabo por Úriz al frente del obispado de Lleida.

\section{Principales tareas de ÚRIZ en el obispado de Lleida:}

\section{El Seminario Conciliar}

Los Seminarios Conciliares siempre han sido una parte clave e imprescindible de la estructura de poder y transmisión ideológica y cultural de la iglesia, pues en ella se educa a los jóvenes que quieren consagrar su vida a las funciones del ministerio parroquial. En los seminarios se proporciona y adquiere instrucción religiosa, los principios morales, las bases científicas, las directrices de abnegación y los hábitos sacerdotales necesarios para ejecutar su futura tarea pastoral. La importancia y trascendencia histórica jugada por algunos seminarios diocesanos, como el floreciente de Vic dónde se formaron personalidades como Jaume Balmes, no puede trasladarse al centro formativo ilerdense. Por cierto fue uno de los mayores seminarios españoles en número de seminaristas durante las décadas de los años 50 y 60 . Las causas que provocaron esta

\footnotetext{
${ }^{11}$ Temática desarrollada en Closa, F. 2003: 159-170.
} 
situación todavía no han sido analizadas. A pesar de todo quisiéramos apuntar tres posibles hipótesis que deberían verificarse en próximos estudios. En primer término, la proximidad de un centro universitario de importancia como el de Cervera que acaparó, especialmente durante el siglo XVIII, gran parte de los recursos económicos con que se dotaban a los centros educativos provinciales. ${ }^{12}$ En segundo término, la imposibilidad de los diversos prelados de la sede ilerdense para buscar recursos económicos alternativos con que financiarlo. Finalmente hace falta subrayar la notoria presencia entre el profesorado y el alumnado del Seminario de postulados católicos divergentes a los mayoritariamente aceptados. Con respecto a esta cuestión el obispo Rentería ${ }^{13}$ decía lo siguiente a las puertas del Trienio: «A pesar de mi vigilancia por conservar la sana doctrina, y de las gestiones que hice para ello, representando contra el establecimiento de la teología llamada de León para la enseñanza, se introdujo con mucho dolor de mi corazón, el amor a las nuevas doctrinas contrarias a la religión, y derechos de la Iglesia y del Soberano...». ${ }^{14}$

El Concordado de 1851 restauró los Seminarios en las capitales de cada diócesis. El gobierno y su dirección correspondía a los diocesanos -en sede vacante ni el capítulo ni el vicario capitular podían modificar ningún elemento- hecho que teóricamente les aseguraba cierta libertad de acción. A pesar de todo, tanto los fundamentos como las diversas medidas pactadas entre el Nuncio Apostólico y el Ministro de Gracia y Justicia en el acuerdo concordatorio, permiten divisar y auspiciar una posible intervención del Estado en materia de enseñanza religiosa. Veamos algunos ejemplos bien significativos. Para empezar podemos mencionar que la elección del rector y de los catedráticos era competencia del prelado el cual, muy a menudo, se encontraría atado de manos por la Reina quien en último término daba o no su aprobación. Los estatutos y planes de estudios serían uniformes para todo el reino y se formarían mediante una junta mixta formada por representantes del Vaticano y del gobierno de Madrid. Además los prelados de cada obispado habían de escoger los libros de texto

\footnotetext{
${ }^{12}$ Prats, Joaquim. 1988. La Universidad de Cervera en el siglo XVIII: Barcelona: Publicacions Universitat de Barcelona.

${ }^{13}$ Sobre este obispo pueden consultar el artículo Sanchez Carcelen, Antonio. 2005. «La repressió dels eclesiàstics absolutistes lleidatans al Trienni Liberal: el cas del bisbe Renteria», Revista HMiC: història moderna i contemporània 3: 351-372. Para esta época en Lleida pueden consultar: Sánchez i Carcelén, Antonio. 2007. «La repercusión del régimen constitucional en la Iglesia de Lleida durante el trienio liberal». Hispania sacra 119, 323-336; Sánchez i Carcelén, Antonio. 2009. Els defensors de Ferran VII a Lleida (1823-1833): Lleida: Universitat de Lleida; Sánchez i Carcelén, Antonio. 2010. «Eclesiásticos catalanes y las Cortes de Cádiz». Anuario de historia de la Iglesia 19: 119-140 y Sánchez i Carcelén, Antonio. 2012. Absolutisme i liberalisme: l'Església de Lleida durant el regne de Ferran VII: Barcelona: Ajuntament de la Pobla de Claramunt.

14 Viola, Ramiro. 1983. El Seminario de Lérida conocido y frecuentado por el padre Palau: 13 Roma: Carmelitas Misioneras Teresianas.
} 
empleados por los seminaristas entre un listado propuesto por el Gobierno. De hecho se estaba llevando a término cierta equiparación -incluso afirmaríamos que sometimiento- de los seminarios a las normas definidas para los centros universitarios y los institutos. ${ }^{15}$

Pero la implicación gubernamental fue más allá al inmiscuirse en tareas que desde tiempos remotos habían sido monopolio exclusivo de la Iglesia católica. Así establecieron las costumbres y conductas que debían seguirse en todos los seminarios de la Corona española y las posibles faltas que podrían imponerse a los seminaristas. Desde esta óptica también hemos de mencionar la definición estatal de asistencia a las funciones religiosas -todos los días festivos y a las rogativas y procesiones generales- y en el número y categoría de los alumnos. En el Concordado se definía que: «en los seminarios habrá dos clases de alumnos. Los primeros será la de los naturales de la diócesis que obtengan las becas de número gratuitas; y la segunda la de los que pagando sus alimentos sigan el mismo método de vida que los primeros. El número de becas gratuitas se fijará en proporción al de los eclesiásticos que necesite la diócesis, y el de los pensionistas podrá ser el que permita el edificio y los demás medios del colegio». ${ }^{16}$ En último término no podemos obviar un elemento tan importante como el mantenimiento económico de los Seminarios. Su dotación consistía en la comunión entre las dotaciones obtenidas por el producto de arbitrios y bienes, cuantitativamente muy reducidas, y las asignaciones establecidas en los presupuestos generales del estado en concepto de culto. Desde entonces se dictaran varias medidas encaminadas a mejorar la empobrecida situación de los seminarios siempre con el consentimiento de los diversos gobiernos moderados quienes, excepto en contadas ocasiones, aceptaron sin demasiados miramientos las propuestas de los diocesanos. Ahora bien, la puerta abierta que el concordado dejaba al intervencionismo estatal en materia religiosa se puso especialmente de manifiesto durante el Bienio Progresista (1854-1856). ${ }^{17}$ Entonces, cómo podemos observar en el siguiente cuadro, incidieron notoriamente con el buen desarrollo de los proyectos eclesiásticos mediante la reducción económica del presupuesto destinado a culto y clero y paralizaron la aprobación de prerrogativas en materia religiosa.

\footnotetext{
${ }^{15}$ Reglamento para la ejecución del plan de estudios decretado por su Majestad el 17 de setiembre de 1845: Madrid: 1845.

${ }^{16}$ Citado en la obra de Pérez Alhama, Juan. 1967. La iglesia y el estado español: 484 Madrid: Instituto de Estudios Políticos. También puede consultarse en el artículo 28 del Concordato. Nosotros utilizamos el publicado en el BEOL, núm. 17, 1853, 137-148.

${ }^{17}$ Los enfrentamientos con el Gobierno Central y con el consistorio municipal han sido desarrollados en Closa, F. 2003: 111-125.
}

Hispania Sacra, LXVII

136, julio-diciembre 2015, 673-715 ISSN: 0018-215X, doi: 10.3989/hs.2015.020 


\section{Cuadro 1: Presupuesto estatal establecido para el clero español (1855-1856):}

\begin{tabular}{|l|r|r|r|}
\hline \multicolumn{1}{|c|}{ Concepto } & \multicolumn{1}{c|}{$\begin{array}{c}\text { Crédito de } \\
\mathbf{1 8 5 5}\end{array}$} & $\begin{array}{c}\text { Crédito de } \\
\mathbf{1 8 5 6}\end{array}$ & \multicolumn{1}{c|}{ Diferencia } \\
\hline Pago al clero secular & 119.095 .459 & 112.789 .534 & -6.305 .925 \\
\hline Material del clero secular & 44.344 .964 & 38.787 .182 & -5.557 .782 \\
\hline Personal de religiosas de clausura & 11.705 .655 & 11.283 .238 & -422.417 \\
\hline Personal de tribunales y oficinas eclesiásticas & 687.000 & 606.000 & -81.000 \\
\hline TOTAL & 175.833 .078 & 163.465 .954 & -12.367 .124 \\
\hline
\end{tabular}

Fuente: elaboración propia a partir de los datos de la Gaceta de Madrid, 29 octubre 1855.

Uno de los hechos que más impactó a Úriz desde su llegada a Lleida fue el deplorable estado en que se encontraba el Seminario Conciliar, consecuencia de las guerras, especialmente las carlistas, que habían asolado gran parte de la provincia hasta entonces. ${ }^{18}$ Con el fin de mejorarlo estableció una serie de importantes medidas. Analicémoslas someramente: a) Ensanchamiento del edificio con la construcción de nuevas alas, donde podían albergarse más aulas y estudiantes, adaptándose a las nuevas asignaturas del recién estrenado plan de estudios $;{ }^{19}$ b) Reorganización de la parte moral del clero: mejora de la obediencia y los aspectos relacionados con el trato social, la simpatía, la cortesía, la decencia para cautivar y ganar el respecto de los futuros feligreses, c) Mejora de la estructura del profesorado con la creación de nuevas cátedras y de nuevos profesores para sustituir a los posibles enfermos; d) Reestructuración de las infraestructuras pedagógicas con la creación de una moderna Biblioteca del Seminario, el inicio de ejercicios espirituales y la enseñanza de la liturgia sagrada, e) La implantación completa de los nuevos planos de estudios establecidos a nivel nacional, ${ }^{20}$ f) La asistencia y control personal del obispo en los diversos actos celebrados por esta institución, ${ }^{21}$ pues sus antecesores habían dejado totalmente desatendida y descontrolada esta básica institución de la jerarquía diocesana.g)

${ }^{18}$ Este proceso ha sido analizado en nuestro artículo: Closa, Francesc. 2003. «El poder eclesiàstic a Lleida (1800-1905): entre l'immobilisme i el regeneracionisme social», en Xavier Eritja, Joan Sagués y Maite Solanes (a cura de), Conèixes la teva ciutat...? Lleida vuitcentista. XXIII Campanya, març de 2003: 41-76. Lleida: Ateneu Popular de Ponent.

${ }^{19}$ Además se realizarían con mayores garantías higiénicas y de salubridad.

${ }^{20} \mathrm{Su}$ íntegra reproducción puede consultarse en el BEOL, núm. 6, 19 julio 1853,43-48 y en el núm. 7, 1 agosto $1853,51-55$.

${ }^{21}$ De hecho asistirá a la apertura de todos los cursos académicos y lo visitará por sorpresa en varias ocasiones aprovechándolo para visitar las instalaciones y conversar con alumnos y maestros. Puede observarse en el BEOL, núm. 10, 15 septiembre 1853, 73. 
Creación de becas que pagaba personalmente Úriz. h) Instauración de la fiesta del Seminario el primer domingo del mes de octubre con la realización de varios actos de puertas abiertas y sermón del propio obispo. ${ }^{22}$

Entre las novedades también figuraba el establecimiento de nuevas pruebas de acceso. Durante algunos siglos el acceso al mundo eclesiástico había sido únicamente un método de prestigio social, y esto había perjudicado seriamente la agricultura local. Muchas familias preferían enviar a sus primogénitos al Seminario, donde disfrutaban de alimento, acceso a la cultura y la posibilidad de ascender en su estructura jerárquica y social, abandonando los problemas y carencias surgidas de una economía esencialmente agrícola sin modernización y a merced de la climatología. Ahora era el Estado quien establecía y fijaba el número de miembros de cada diócesis, catedral y seminario y quien los financiaba. Esto, en cierto modo, obligaba a los prelados a endurecer unas pruebas que por su naturaleza estaban siendo reducidas. En principio, los únicos requisitos para solicitar plaza como seminarista era presentar los certificados de bautismo. En el caso de los jóvenes procedieran de otra diócesis, habían de acompañarlo con una certificación de buena conducta. Sólo se permitiría matricularse a aquellos que quisieran ser promovidos al sacerdocio. Los seminaristas que no aprobaran algún curso y los que no obedecieran las normativas internas serian rápidamente expulsados. Aun así, establecía un número de becas a las cuales podían acceder únicamente la gente nacida en el obispado que presentaran un certificado médico manifestando el buen estado de salud del aspirante y la garantía sanitaria que ninguna patología física impediría que pudiera ejercer en años posteriores el sacerdocio. ${ }^{23}$

El ímpetu y la fuerza con que Úriz había desembarcado en la diócesis ilerdense eran incuestionables. Pero la realidad era mucho más compleja. La pretérita y privilegiada situación de la iglesia había menguado. Las iniciativas realizadas por Pedro Cirilo se paralizaron durante el Bienio Progresista. De hecho el gobierno progresista suprimió a nivel estatal la segunda enseñanza, prohibió los sagrados cánones y limitó la enseñanza de los estudios teológicos rompiendo con el arreglo de parte de los negocios eclesiásticos realizados en los años anteriores. Además, como manifestábamos anteriormente, la reducción del presupuesto eclesiástico dirigido a la diócesis ilerdense tampoco le fue gratificante.

\footnotetext{
${ }^{22}$ BEOL, núm. 11, 30 septiembre 1853,82 .

${ }^{23}$ BEOL, núm. 9, 23 agosto 1853, 65-67. En dicho número del boletín eclesiástico de la diócesis dejaba bien claro la precaria situación espiritual del obispado y los múltiples problemas económicos de la iglesia española en general y la de Lleida en particular. Por ello era necesario e imprescindible restringir el acceso al sacerdocio e intentar que de cada semilla plantada (cada seminarista) saliera un buen capellán.
}

Hispania Sacra, LXVII

136, julio-diciembre 2015, 673-715 ISSN: 0018-215X, doi: 10.3989/hs.2015.020 


\section{Cuadro 2: cantidades asignadas por el Estado a las tres diócesis comprendidas en la provincia civil de Lleida (1854-1855):}

\begin{tabular}{|l|c|r|c|}
\hline \multirow{2}{*}{ Diócesis } & \multicolumn{2}{|c|}{ Cantidad asignada por año } & \multirow{2}{*}{ Diferencia } \\
\cline { 1 - 1 } Lleida & 1854 & 1855 & \\
\cline { 1 - 1 } Solsona & 1.717 .429 & $1.591 .654^{\prime} 39$ & -125.775 \\
\hline Seu d'Urgell & 1.030 .932 & $947.012^{\prime} 24$ & -83.920 \\
\hline TOTAL & 2.237 .969 & $2.109 .510^{\prime} 30$ & -128.459 \\
\hline
\end{tabular}

Fuente: elaboración propia a partir de: Obligaciones eclesiásticas. Clero secular. Religiosas en clausura 1855, Arxiu Històric Provincial de Lleida, ${ }^{24}$ sig. núm. 2895.

En cambio el nuevo gobierno moderado surgido el 1856 retornaba vientos altamente favorables para los planes de Úriz. Así, por ejemplo, restauró las antiguas leyes pues la reina, según palabras del propio obispo: «se interesa a la vez cono la Iglesia de esa institución, que deben recoger el fruto de esa saludable institución, destinada a formar, bajo reglas acertadas, virtuosos e instruidos sacerdotes».$^{25}$ Era imprescindible retomar la tarea iniciada antes de la tormenta del bienio. La precaria situación del obispado le obligaba a ello: «existen públicas blasfemias y escandalosos concubinatos. Son varios los pueblos de la Diócesis que tienen que lamentar tan graves males, y que especialmente cuentan con matrimonios desunidos, llegando hasta el exceso de existir tres en uno de escaso vecindario». ${ }^{26}$

En términos generales el nuevo rumbo político fue excepcionalmente positivo para la iglesia leridana. A pesar de las privaciones establecidas durante el Bienio Progresista los esfuerzos del prelado continuaron perdurando en el tiempo. Así, por ejemplo, se había mejorando y ampliando el número de habitaciones del Seminario. Ello precisaba la aprobación del Consistorio Municipal. El 1857 Florencio Vistuer, vice-rector del Seminario, hacía una petición al consistorio municipal leridano para abrir nuevas ventanas y puertas en el nuevo Seminario. La solicitud se acompañaba con la demanda de respuestas a las molestias que les ocasionaban las aguas residuales y de la lluvia procedentes del Castillo. Además proponía la necesidad de construir un muro y unas cloacas para facilitar su evacuación. El ayuntamiento, haciéndose eco del citado escrito, acordó por unanimidad el nombramiento de una comisión encabezada

\footnotetext{
${ }^{24}$ Archivo Histórico Provincial de Lleida (a partir de este momento AHPL).

${ }^{25}$ BEOL, núm. 100, 30 octubre 1856, 355-357.

${ }^{26}$ Esta y otras justificaciones pueden reseguirse en el BEOL, núm. 94, 30 agosto 1856, 259-263.
} 
por el arquitecto municipal. Tras visitar las obras presentó un informe positivo. El gobierno municipal, leído y analizado el informe, dio permiso para la ampliación del Seminario.$^{27} \mathrm{~A}$ su vez inició las necesarias gestiones para solucionar los citados problemas de humedad. Todo esto parece indicar que al ayuntamiento de Lérida, por una parte, le interesaba gestionar rápidamente una serie de problemas de carácter urbanístico que potencialmente no le eran favorables y, por otra parte, quería reducir los enfrentamientos con la iglesia local. El mismo año 1856, el obispo y el capítulo catedralicio ampliaban la oferta de becas y animaban a la juventud a matricularse libremente..$^{28} \mathrm{~A}$ nivel estatal los Seminarios cada vez se vieron más reforzados y protegidos por la monarquía y los gobiernos moderados. El año 1858, por ejemplo, el Ministerio de Fomento permitía la convalidación de las asignaturas cursadas en los Seminarios por algunas ofertadas en los centros de Segunda Enseñanza y en las Universidades.

Por tanto los acuerdos, decisiones y actuaciones pactados a escala local entre 1850-54 recibieron un golpe de muerte durante el bienio progresista. Pero la reaparición de los moderados en la escena política los retomaron estimulando y propiciando la acomodación de la Iglesia al estado con el fin, en palabras de la propia reina, «de mejorar los intereses de la Iglesia como los del Estado». ${ }^{29}$

A pesar de ello si nos atenemos al cuadro 3 podremos observar una doble tendencia. Durante el curso 1852-53, los estudiantes del Seminario de Lleida habían alcanzado la cifra de los 450 . De estos, 85 eran internos y 355 externos. ${ }^{30}$ A pesar de los esfuerzos del prelado el año 1868 el número de seminaristas había disminuido considerablemente hasta los 252 (53 de internos y 199 de externos). ¿Qué podía explicar esta drástica pérdida de 200 alumnos? La respuesta no se muestra fácil. Puede orientarnos el hecho que las cifras de seminaristas a nivel nacional, y en otras diócesis como la de Pamplona ${ }^{31}$ reflejan el mismo declive. El año de la Gloriosa había en España 44.735 seminaristas, número muy inferior a los 57.892 existentes 40 años atrás. ${ }^{32}$

${ }^{27}$ El proceso puede consultarse en el Arxiu Municipal de la Paeria (archivo municipal de Lleida, AMP), Actas Municipales, 22 abril 1857.

${ }^{28}$ BEOL, núm. 100,30 octubre $1856,363$.

${ }^{29}$ BEOL, núm. 179, 23 octubre $1858,372-374$.

${ }^{30}$ BEOL, núm. 4, 30 junio $1853,25-30$.

${ }^{31}$ Según Cuenca Toribio, J.M. 1980: 129-130, este obispado perdió el 22,1\% de sus seminaristas.

${ }^{32}$ Lo mismo sucedió con las órdenes monásticas. El año 1826 en España había 92.627 clérigos repartidos en más de 3.000 conventos. Tiempo después, en 1862, la cifra descendía hasta los 1.746 religiosos y 13.347 religiosas. La recuperación a lo largo del siglo xIx fue muy lenta pero progresiva aunque nunca volvieron a darse datos parecidos a los anteriores de las desamortizaciones. 


\section{Cuadro 3: Número de seminaristas existentes en las diócesis catalanas (1868-1891):}

\begin{tabular}{|l|c|c|c|c|c|}
\hline Diócesis & $\begin{array}{c}\mathbf{1 8 6 8} \\
\text { Internos }\end{array}$ & $\begin{array}{c}\mathbf{1 8 6 8} \\
\text { Externos }\end{array}$ & $\begin{array}{c}\text { Total } \\
\mathbf{1 8 6 8}\end{array}$ & Total 1883 & Total 1891 \\
\hline Barcelona & 122 & 410 & 532 & 732 & 514 \\
\hline Girona & 63 & 492 & 555 & 902 & 656 \\
\hline Lleida & 53 & 199 & 252 & 342 & 405 \\
\hline Solsona & 32 & 235 & 267 & 237 & 260 \\
\hline Tarragona & 188 & 116 & 304 & 363 & 354 \\
\hline Tortosa & 82 & 386 & 468 & 517 & 850 \\
\hline Urgell & 42 & 341 & 383 & 617 & 433 \\
\hline Vich & 31 & 1.054 & 1.084 & 912 & 1.000 \\
\hline
\end{tabular}

Fuente: elaboración propia a partir de los datos ofrecidos por Carcel Ortí, Vicente. 1975. «El clero durante la revolución de 1868 y la Primera República española», Analecta Sacra Tarraconensia XLVIII: 152-153, «Los estudios eclesiásticos en Cataluña y la Pontificia Universidad de Tarragona (1897-1934)», 2001: XX Siglos 2: 31-40 y en el capítulo «Enseñanza eclesiástica durante el año escolar 1883-1884», Anuario 1888: 102-103.

Por el contrario la dinámica descrita viraría durante el último tercio del siglo llevando a cabo una importante recuperación. De hecho, como afirma Aubert, la recuperación fue lenta pero progresiva.$^{33} \mathrm{La}$ tarea de Úriz en el campo seminarístico tiene que analizarse y verse como un intento para conseguir frenar y mejorar el substrato existente. Podríamos concluir este capítulo afirmando que las mejoras introducidas por Pedro Cirilo Úriz en la diócesis de Lleida fueron, a largo plazo, del todo positivas y fructíferas. Supo poner orden espiritual, económico y pedagógico en un importante ámbito eclesiástico -el del aprendizaje religioso- desatendido durante largos años.

\section{El arreglo de la diócesis}

Otra de las importantes tareas desarrolladas por Pedro Cirilo Úriz en el aspecto diocesano fue la dirigida, en primer término, a mejorar la estructuración del espacio interno del obispado y, en segundo lugar, el arreglo parroquial. El obispado de Lérida tenía una serie de peculiaridades que lo diferenciaban del resto. Estas pueden resumirse en tres. En primer término su delimitación

\footnotetext{
${ }^{33}$ Aubert, Roger. 1974. Historia de la Iglesia. Pío IX y su época, vol. XXIV 198 Valencia: EDICEP.
} 
geográfica a mediados del siglo XIX abarcaba sustancialmente el mismo ámbito que durante el XVIII. ${ }^{34}$ Pascual Madoz recordaba la dificultad de analizarlo debido a la irregularidad extraordinaria de su división eclesiástica. ${ }^{35} \mathrm{Su}$ orografía era extremadamente diversa. Las zonas llanas de Lérida y Monzón contrarrestaban con las del Pirineo catalán y aragonés. Las carreteras continuaban siendo de herradura hecho que imposibilitaba unas condiciones aceptables para el transporte. Las distancias se hacían muy largas. Ello conllevaba que algunas poblaciones estuvieran a más de cuatro horas de la capital diocesana.

En segundo lugar las dificultades para delimitar el espacio geográfico del obispado. Hacemos referencia a la existencia de cuatro territorios con jurisdicciones eclesiásticas propias: el arciprestazgo de Ager, con jurisdicción exenta vere nullius, el abadiato de Labaix, el de la $\mathrm{O}$ y el priorato de Meyá. Todos ellos a partir del Concordato de 1851 pasaban a formar parte del obispado de Lleida pero su materialización se prolongaría hasta mediados de los años setenta.

En tercer lugar su variopinta distribución administrativa. La totalidad de las parroquias se encontraban repartidas en tres diferentes provincias administrativas (Lleida, Huesca y Zaragoza). Decía el obispo Huix y Miralpeix a mediados de los años treinta con referencia a este particular: «Entre las diócesis de España, Lérida tiene singular importancia y dificultad. (...) tiene una gran cantidad de parroquias en la provincia de Huesca y algunas en la de Zaragoza. Esto hace que sea difícil la labor del Obispo, que no puede contar con una uniformidad de carácter, de costumbres, ni aun de religiosidad entre sus diocesanos». ${ }^{36}$ Además los pueblos de la provincia de Lleida estaban distribuidos entre las diócesis de Lleida, la Seu d'Urgell, Solsona, Tarragona, Tortosa y Vic. Veamos algunos ejemplos bien significativos. En el obispado de Urgel había 55 parroquias que pertenecían al obispado de Lleida. Dentro de este último estaban enclavados el pueblo de Torrelarribera, que pertenecía a la diócesis de Barbastro y el oficialato de Aren, que era del de Urgel..$^{37}$

\footnotetext{
${ }^{34}$ Hemos desarrollado el tema del arreglo parroquial y las demarcaciones diocesanas en Lleida en el artículo Closa, Francesc. 2002. «Les demarcacions diocesanes i els arranjaments parroquials, instruments per a la reconstrucció dels bisbats: el cas de la diòcesi de Lleida (1800-1905)», Segon Congrés Recerques. Enfrontaments civils: postguerres i reconstruccions: 492-512 Lleida: Servei de Publicacions de la Universitat de Lleida.

${ }^{35}$ Madoz, Pascual. 1985. Diccionario geográfico-estadístico-histórico de España: 30-32 Barcelona: Biblioteca Santa Ana.

${ }^{36}$ Tibau Duran, Narciso. 1948. Apuntes biográficos del Excmo. y Rvdmo. P. Salvio Huix Miralpeix, obispo de Lérida: 88 Lérida: Artis Estudios Gráficos.

${ }^{37}$ Fuentes, Primitivo. 1848. Guía del estado eclesiástico de España y de los dominios de S.M. en América y Asia para el año de 1849, redactada y publicada con real permiso; Madrid: Ministerio de Gracia y Justicia.
} 


\section{Cuadro 4: Ubicación provincial de los pueblos del obispado ilerdense en 1853:}

\begin{tabular}{|l|c|c|c|}
\hline Provincia & Número de pueblos & $\begin{array}{c}\text { Número de } \\
\text { conventos }\end{array}$ & $\begin{array}{c}\text { Número de } \\
\text { eclesiásticos }\end{array}$ \\
\hline Lleida & 90 & 11 & 81 \\
\hline Huesca & 145 & 15 & 125 \\
\hline Zaragoza & 2 & ------ & $-\cdots---$ \\
\hline Total & 237 & 26 & 206 \\
\hline
\end{tabular}

Fuente: elaboración propia.

El Concordato de 1851 era consciente de esta problemática generalizada en muchas diócesis y por ello contemplaba varios puntos que intentarían darle respuesta. La reestructuración diocesana y el arreglo parroquial tienen que apreciarse como elementos modernizadores pues distribuirían el territorio atendiendo a la extensión, la naturaleza del territorio, la población, la historia así como las diversas circunstancias locales y particulares ${ }^{38}$ La demarcación diocesana suponía el establecimiento de los límites de cada obispado. Por su parte el arreglo parroquial tenía su sostén en el número de arciprestazgos y parroquias que conformarían cada territorio eclesiástico así como la categoría de cada una de ellas. Ello comportaría una diferente asignación económica. Los diversos prelados serían los encargados de realizar los estudios y proponer los cambios que consideraran oportunos, pero el Gobierno se reservaba la potestad de aceptarlos o bien rechazarlos. A pesar de las disposiciones concordatorias su ejecución definitiva se pospuso durante largos años. En Lleida un enérgico Úriz realizó una ardua tarea para racionalizar la diócesis. Veamos algunos ejemplos muy significativos. El año 1853, recién estrenado en su nuevo territorio eclesiástico, creó dos nuevos arciprestazgos, los de Tamarite y Tolva, con el fin de mejorar el servicio espiritual y reformó el número de parroquias existentes en cada zona. El nuevo cuadro parroquial quedaba regulado de la siguiente manera. La diócesis quedaba distribuida con un total de ocho arciprestazgos. Las zonas más llanas de la diócesis, las de Lleida y Monzón, tenían un mayor número de parroquias, pues las infraestructuras existentes y sus aspectos geográficos permitían un rápido traslado desde Lleida. En cambio, las parroquias sitas en las zonas más alejadas y más abruptas geográficamente hablando, se encontraban distribuidas en arciprestazgos más pequeños dónde, al menos teóricamente, el control era de esta manera más fácil de ejercer.

\footnotetext{
${ }^{38}$ BEOL, suplemento al número $17,1853,137-148$. Son especialmente interesantes los artículos 7 y 24 .
} 
Cuadro 5: Número de arciprestazgos y parroquias de la diócesis de Lleida (1853):

\begin{tabular}{|l|c|}
\hline \multicolumn{1}{|c|}{ Arciprestazgo } & Número de parroquias \\
\hline Tamarite & 16 \\
\hline Tolva & 23 \\
\hline Benavarre & 12 \\
\hline Roda & 25 \\
\hline Fraga & 19 \\
\hline Monzón & 31 \\
\hline Lérida & 59 \\
\hline
\end{tabular}

Fuente: elaboración propia a partir de BEOL, núm. 1, 14 mayo 1853, 4-6.

El número y la categoría de las 204 parroquias del obispado también reflejaban notables diferencias. A nivel general puede observarse (cuadro 6) la numerosa existencia de parroquias con la categoría de ascenso seguidas por las de entrada y, finalmente, las de término. Estas últimas se encontraban concentradas en el arciprestazgo de Lleida donde el número de fieles era mayor. Por lo tanto, la categoría y las cantidades económicas establecidas eran más importantes. Por el contrario, los arciprestazgos de montaña con un menor peso demográfico y un hábitat más disperso, como las de Roda y Vilaller, recibían las peores categorías y consecuentemente las asignaciones económicas más bajas.

\section{Cuadro 6: Número de parroquias según su categoría en cada arciprestazgo antes del arreglo parroquial:}

\begin{tabular}{|l|c|c|c|c|}
\hline Arciprestazgo & Término & Ascenso & Entrada & Total \\
\hline Lleida & 12 & 35 & 7 & 57 \\
\hline Benavarre & 1 & 5 & 6 & 12 \\
\hline Fraga & 2 & 14 & 3 & 19 \\
\hline Monzón & 3 & 22 & 9 & 34 \\
\hline Roda & ---- & 3 & 22 & 25 \\
\hline Tamarite & 6 & 3 & 7 & 16 \\
\hline Tolva & 2 & 11 & 6 & 19 \\
\hline Vilaller & ---- & 10 & 12 & 22 \\
\hline Total & 26 & 103 & 74 & 204 \\
\hline
\end{tabular}

Fuente: elaboración propia.

Hispania Sacra, LXVII

136, julio-diciembre 2015, 673-715 ISSN: 0018-215X, doi: 10.3989/hs.2015.020 
La racionalización de los arciprestazgos estuvo acompañada por la recogida de los primeros datos para el establecimiento del arreglo parroquial. Tres eran los fundamentos principales de los nuevos planes parroquiales: en primer lugar, mejorar la distribución del ejercicio espiritual, clasificando la calidad de los pastores, cargos y distritos parroquiales; en segundo término, normalizar y mejorar las retribuciones económicas que recibían los curas tras la supresión de los diezmos, mejorando las reales órdenes de los años 1839 y 1845 y, en último lugar, complementar y suplir el papel jugado pretéritamente por las comunidades religiosas, ahora desaparecidas. El 9 de enero de 1854 Úriz dio lugar a la formación del expediente para el arreglo parroquial, tras publicar la noticia en el Boletín Eclesiástico. ${ }^{39}$ Un año y medio tardaría en ultimar las diligencias de su estudio serio y profundamente analítico. Mientras estas duraran tuvo algunos enfrentamientos con el equipo de gobierno local. Las primeras divergencias se establecieron en el momento de cifrar los habitantes de Lleida. Mientras Úriz contabilizaba alrededor de 18.298, el Ayuntamiento reducía la cifra hasta los 15.000. El consistorio municipal entendía que 5 parroquias a la ciudad eran excesivas, y pedía la creación de tres demarcaciones parroquiales: zona central (Catedral), parte alta (Sant Llorenç como centro) y los alrededores de Santa Maria Magdalena. ${ }^{40}$ Por el contrario, el arreglo propuesto por Úriz respetaba las cinco demarcaciones tradicionales, dando a todas ellas la categoría de parroquia de término (cuadro 8). Santa Maria Magdalena resultaba así mejorada, pues pasaba de ascenso a término, es decir, de un único vicario a un rector y dos coadjutores. ${ }^{41}$ Finalmente no hubo entendimiento pero tampoco ningún cambio significativo.

A pesar de la buena disposición del prelado leridano para la ejecución de los acuerdos concordatorios, la inestabilidad política, la alternancia entre moderados y progresistas en el poder y la caótica situación de las arcas públicas beneficiaran continuos aplazamientos. El 31 de agosto de 1855, por ejemplo, Pedro Cirilo Úriz remitía una carta al Ministro de Gracia y Justicia dónde le recordaba que ya le había enviado el arreglo parroquial correspondiente a los arciprestazgos de Lleida, Monzón, Tamarite y Fraga, dónde había 126 parroquias de las 204 que conformaban la totalidad del obispado. Además le notificaba que estaba recogiendo la información para hacer el mismo a los de Benabarre, Rueda, Tolva y Vilaller y los territorios de Ager, Meyà, la O y Labaix. Pretendía presentarlo conjuntamente, pero la aparición del cólera-morbo en 55 parroquias se lo había

\footnotetext{
${ }^{39}$ Aprovecharía la ocasión, a pesar del triunfo de los progresistas, para llevar a término una visita pastoral por parte del obispado, BEOL, núm. 18, 13 enero 1854, 154-167.

${ }^{40}$ AMP, caja 428, 1855.

${ }^{41}$ En los planes del prelado también estaba el nacimiento de un nuevo mapa apostólico mediante la aparición de cofradías y entidades católicas que, con estructura de base parroquial, hacían de la parroquia el centro y motor de la acción católica.
} 
imposibilitado. Las parroquias insertadas en el arreglo eran las más numerosas en fieles. Las 78 restantes estaban situadas en las zonas más alejadas y abruptas del Pirineo y muchas de ellas eran rurales.

Los datos que hemos podido recopilar hasta el momento son parciales. Por ello vamos a centrarnos en el arciprestazgo de Lleida dándonos la posibilidad de hacernos una idea general y esbozar de la tendencia que probablemente siguió. El arreglo propuesto por Pedro Cirilo Úriz mantenía el número de curas, pero ampliaba considerablemente el de coadjutores pasando de los tres a los 49 . La causa debe buscarse en la mala situación del Seminario Conciliar y de la hacienda pública. Para ambos instituciones, resultaba más económico el mantenimiento de cuerpos jerárquicos menores. Con este aumento podía hacerse frente a la espiritualidad de los fieles, pero todavía carecía de solución el estado económico de los parroquianos. La clasificación de cada parroquia establecía también la cantidad económica que debía percibir en concepto de culto y personal. El siguiente cuadro indica como pretendía mejorarla estableciendo la categoría máxima posible.

\section{Cuadro 7: Arreglo parroquial previsto por el obispo Úriz para el arciprestazgo de Lleida (1857):}

\begin{tabular}{|l|c|c|}
\hline Categoría & $\begin{array}{l}\text { Clasificación de les parroquias } \\
\text { actuales }\end{array}$ & Clasificación según el arreglo \\
\hline 1r. Ascenso & 12 & $14^{42}$ \\
\hline 2o. Ascenso & 22 & 6 \\
\hline Término & 12 & 33 \\
\hline Entrada & 6 & ---------- \\
\hline Anejas & 1 & 1 \\
\hline Rurales de $1^{\text {a }}$ & ---------- & ---- \\
\hline
\end{tabular}

Fuente: elaboración propia a partir del Expediente general de arreglo de parroquias, AMJ, legajo 3.836 , expediente 15.483 .

En términos económicos esto suponía pasar, en el tema de dotación para personal, de los 288.600 reales de vellón abonados anualmente hasta los 307.500 rv previstos según el arreglo. (Anexo 1) Gran parte del incremento se observa

\footnotetext{
${ }^{42}$ En los datos del arreglo propuestos por Pedro Cirilo Úriz constan conjuntamente las parroquias de primero y segundo ascenso

Hispania Sacra, LXVII

136, julio-diciembre 2015, 673-715 ISSN: 0018-215X, doi: 10.3989/hs.2015.020
} 
en el ascenso de categoría de las parroquias de Lleida. (Cuadro 8) Estas veían aumentado la dotación de personal de los 29.300 rv cobrados entonces hasta los 48.000 rv previstos.

\section{Cuadro 8: Relación entre las clasificaciones y las dotaciones para personal que recibían las parroquias de Lleida el 1857 y el arreglo propuesto por Úriz:}

\begin{tabular}{|l|l|c|c|c|}
\hline \multicolumn{1}{|c|}{ Parroquia } & $\begin{array}{c}\text { Clasificación } \\
\text { actual }\end{array}$ & $\begin{array}{c}\text { Clasificación } \\
\text { según arreglo }\end{array}$ & $\begin{array}{c}\text { Dotación } \\
\text { personal actual }\end{array}$ & $\begin{array}{c}\text { Dotación personal } \\
\text { según arreglo }\end{array}$ \\
\hline St. Pere & 2o. Ascenso & Término & 5.500 & 10.000 \\
\hline St. Llorenç & Término & Término & 7.000 & 10.000 \\
\hline Sta. Magdalena & 1er. Ascenso & Término & 4.900 & 9.000 \\
\hline St. Andreu & 1er. Ascenso & Término & 4.900 & 9.000 \\
\hline St. Joan & 1er. Ascenso & Término & 7.000 & 10.000 \\
\hline Total & --------- & --------- & 29.300 r.v. & 48.000 r.v. \\
\hline
\end{tabular}

Fuente: elaboración propia a partir del Expediente general de arreglo de parroquias, AMJ, legajo 3.836 , expediente 15.483 .

Los centros parroquiales de Sant Joan y Sant Llorenç mantenían su categoría pero incrementan la dotación establecida, mientras que el resto de las iglesias también aumentaban sus categorías así como las dotaciones para personal establecidas por el Gobierno Central. Por otro lado, las asignaciones establecidas para el culto muestran una análoga tendencia aunque el incremento será menor. Si anualmente el arciprestazgo de Lleida recibía conjuntamente 84.300 rv, Pedro Cirilo Úriz proponía un aumento de 6.300 rv. Por lo tanto, la dotación para culto se fijaba en 90.600 rv. Los efectos económicos de la desamortización sobre el culto habían sido insignificantes, pero sí relevantes en el campo de la dotación de personal.

Era necesario, según Pedro Cirilo Úriz, el aumento del número de curas y su financiación, elementos divergentes de la política seguida hasta entonces por el gobierno progresista y que, posteriormente, a los moderados les costaría iniciar. De hecho la aprobación del plan de Úriz tanto a nivel local como diocesano se demoró varias décadas. Unos años después, concretamente el 1867, la Reina se hacía eco de los déficits del obispado ilerdense. Tanto el Estado central como el propio Úriz, según la monarca, habían hecho todo lo posible para mejorar la situación, pero las circunstancias políticas y sociales impidieron su realización. Conseguir todos estos cambios fue realmente muy lento. A finales de 1868, la reina aprobaba un reglamento provisional para los beneficiados y curas de la 
diócesis ${ }^{43}$ pero la estructura diocesana y el arreglo quedaban todavía por realizarse. A pesar de ello ha de verse como un adelanto importante, pues regulaba la situación de los beneficiados, es decir, mejoraba la situación económica de una pequeña parte de los curas asistentes existentes en varias parroquias y en la catedral. Los intentos de los posteriores prelados -Puigllat ${ }^{44}$ y Costa y Fornagueratampoco llegarían a buen término. Sería definitivamente José Messeguer ${ }^{45}$ quien lo conseguiría el año 1892 después de intensas conversaciones con el ministerio de Gracia y Justicia.

\section{Control ideológico y espiritual del clero:}

A la antigua usanza, el obispo Úriz se estrenó en la diócesis leridana con la publicación de dos cartas dirigidas, respectivamente, al clero y a los fieles de la misma. La exhortación ofrecida a los eclesiásticos de la diócesis era un alegato a los malos vicios del momento y a la función del religioso como pieza clave para frenarlos. La carencia de toda indicación concreta alrededor del programa de su futuro gobierno pastoral constituye, quizás, la principal característica distintiva, que también puede observarse en la primera carta ofrecida posteriormente al clero pamplonica ${ }^{46}$ En aquel caso, Cuenca Toribio cree que es fruto del desconocimiento que tenía Pedro Cirilo Úriz sobre las características de la nueva diócesis. Análogas afirmaciones podemos realizar en el caso concreto del obispado ilerdense. Ahora bien, las continuas referencias a la necesidad de mejorar las condiciones económicas, pedagógicas y espirituales de los rectores, comparadas con parte de la política que seguiría a partir de entonces, hacen cuestionarnos si realmente ya era consciente del mal estado de la diócesis leridana en múltiples aspectos. ${ }^{47} \mathrm{La}$ tesis central defendida por Úriz viene a enfatizar los males o errores establecidos en la sociedad y la relevante misión docente del clero. Pasamos a

\footnotetext{
${ }^{43}$ Reglamento Provisional para los Rdos. Beneficiados o Capellanes asistentes según el Concordato extensivo a los Rdos. Beneficiados laicales al ponerse en planta el arreglo parroquial. Con aprobación real. Con licencia del Señor Obispo, Lérida, 1868.

${ }^{44}$ Un breve resumen sobre las características esenciales pueden encontrarlas en: «Obispado de Lérida. Documentos relativos al arreglo parroquial», BEOL, núm. 68, 24 julio 1867, 329-366. Este obispo reconocería en el mismo número del $B E O L$ citado años después la importante tarea llevada a cabo por su predecesor aunque «las circunstancias políticas y sociales impidieron su realización».

${ }^{45}$ Messeguer, José. 1893. Carta pastoral en el que Ilmo O de Lérida anuncia el planteamiento del nuevo plan y demarcación parroquial: Lérida: Imprenta Mariana. Del mismo obispo; Messeguer, José. 1893. Ampliación del arreglo y demarcación de parroquias del Obispado de Lérida por la restauración de San Martín de la Capital, hecha por el Ilustrísimo José Messeguer y Costa, Obispo de Lérida: Lérida: Imprenta Mariana. También puede encontrarse en el BEOL, núm. 14, 11 julio 1892, 256-265.

${ }^{46}$ Cuenca Toribio, José Manuel. 1969: 129-287.

${ }^{47}$ Úriz, Pedro Cirilo. 1851. Exhortación del Obispo de Lérida a los párrocos y demás eclesiásticos de su Diócesis: Lérida: Imprenta Mariana.
} 
discernir estos exponentes de su mentalidad. La sociedad decimonónica, según el prelado, era un mundo lleno de desorden, vicio y blasfemia dónde imperaba la inmoralidad, la incredulidad y el anticlericalismo, elementos todos ellos, corruptores de las buenas costumbres y la religiosidad social. Bajo el pretexto de una falsa y mal entendida libertad, los gobernantes habían superado los diques de la felicidad para acabar con la perfecta e idílica España. El diagnóstico era claro. Faltaba la solución. En esta tesitura jugarían un papel esencial todo el clero del obispado. Ellos habrían de convertirse en la pieza clave del proceso de normalización católica que impulsaría Úriz. Por ello continuamente les enviaba ánimos. La búsqueda de soluciones por parte de los eclesiásticos merece reproducir el siguiente párrafo. En él ponía en estado de guerra espiritual a los religiosos del obispado: «quitad las marcas del error (...) pero respetad las personas, buscad la conversión de sus almas, curándolas (...) instruiros para instruir á los demás (...) predicad y enseñad sin cesar, pero confirmad cono las buenas obras lo que prediquéis y enseñéis con la palabra. (...) la vida del Eclesiástico no solo debe ser para sí, sino también para los demás. De aquí la necesidad del estudio de la doctrina cristiana». El discurso seguía con las siguientes afirmaciones: «busquemos, procuremos y llamemos por todos los medios las atenciones de los fieles á su felicidad (...) Vean en vosotros las señales de un fino corazón y amor verdadero: vean que en vuestras sencillas exhortaciones solo deseamos su bien espiritual, y entonces serán seguros los adelantamientos». Los curas y eclesiásticos habían de ser el primer paso para frenar la pérdida de fieles, pero previamente era preciso y necesario que estos reciclaran y mejoraran su conducta, formación y presentación a los fieles. Curiosamente, la carta habla de la situación social, pero se centra, a pesar de no haber realizado todavía la visita pastoral, en la situación de la clerecía.

Úriz tenía muy claro, como podremos apreciar posteriormente, que líneas conformarían la esencia vital de sus pastorales. Pero también se dio cuenta desde el principio que la nueva situación concordatoria traería problemas al clero español, pues en términos reales suponía la reducción y privación de sus rentas tradicionales. Ante esta posibilidad, se ofrecía como intermediario con la monarquía, haciéndose eco de sus problemáticas con la convicción personal que «conviene procurar por cuantos medios estén al alcance vivir en armonía y mutuo acuerdo con las autoridades, inculcando lo respeto y la obediencia, que miedo conciencia se debe á las mismas y al gobierno de Su Majestad la Reina». ${ }^{48} \mathrm{Si}$ municipios y rectores se respetaban mutuamente podría beneficiar económicamente a los parroquianos, y serviría como ejemplificación a la ciudadanía de la posición de los gobernantes. Desde los primeros momentos en los cuales Úriz entró al nuevo obispado se dio cuenta, por un lado, de la desmoralización y descristianización de la sociedad y, por otra, la carencia de instrucción

\footnotetext{
${ }^{48}$ Úriz, Pedro Cirilo. 1851: 13.
} 
y de obediencia de curas, beneficiados y coadjutores. Conjuntamente con la realización de concursos sinodales, con el objetivo de proveer plazas de curatos vacantes ${ }^{49}$ gran parte de su tarea pastoral estuvo centrada en la recristianización de la sociedad. Era, pues, necesario previamente instruir la jerarquía diocesana, hecho que puede reseguirse en las visitas pastorales iniciadas el año 1851 y en los primeros números del recientemente creado Boletín Eclesiástico. Rápidamente se convirtió en un elemento imprescindible en la difusión de las ordenanzas de la diócesis y papales. Por lo tanto, constituía un método de intensificar y consolidar la renovación estructural del obispado que Úriz intentaba llevar a cabo. Su publicación suponía la primera aparición de un Boletín Eclesiástico en Cataluña y uno de los primeros de España. En el territorio catalán los obispados de Lleida y de Urgell serían los dos primeros con Boletines, seguidos por los de Vic (1855), Girona (1856), Barcelona, Tortosa (ambos el 1858) y ya en la década de los sesenta por los obispados de Tarragona (1865) y Solsona (1866)..$^{50}$

La correspondencia y los Boletines Eclesiásticos analizados muestran como las órdenes remetidas a los curas se llevaron a término en dos etapas. De una banda, una primera etapa se centró entre los años 1851 a 1853, mientras que una segunda lo hizo a finales de 1857 y todo el año 1858. El lapsus de tiempo existente entre ambas cronologías correspondía al Bienio Progresista. ¿Qué elementos provocaron esta situación? En los casi dos años que perduró el progresismo, Cirilo Úriz varió sus ámbitos de acción y actuación. El cambio coyuntural a nivel nacional le supuso centrarse en la búsqueda de soluciones frente las políticas manifestadamente anticatólicas de los nuevos gobernantes, la consolidación de un espacio de poder -sanidad, beneficencia y enseñanza- con un claro componente de influencia social y, en último término, la publicación de artículos reduciendo las voces antigubernamentales y pro-violentas demostradas en algunas zonas del obispado.

Como decíamos anteriormente, el primer periodo tuvo su epicentro entre los años 1851 y 1853. El objetivo del obispo era reforzar la formación, educación y obediencia de los rectores, piezas claves en el intento recristianizador de la sociedad. La Visita Pastoral ha sido a lo largo del tiempo una de las herramientas primordiales y preeminentes de los obispos para apreciar el estado material y espiritual de fieles y clérigos así como otros elementos que deben tenerse en

${ }^{49}$ Especialmente importantes fueron las realizadas el año 1853 con la que pretendía cubrir más del 50\% de las plazas vacantes. Los resultados fueron relativamente negativos debido a la conjunción de tres elementos: la precaria situación del Seminario Conciliar, el gran déficit de seminaristas desde mediados de los años treinta y, finalmente la política religiosa postulada desde el gobierno progresista. Sobre los concursos a curatos realizados por Úriz consultar: BEOL, núm. 4, 30 junio 1853, 30-31.

${ }^{50}$ Para observar la importancia de estos les remitimos al siguiente artículo de Carcel Ortí, Vicente. 1966. «Los boletines oficiales eclesiásticos en España», Hispania Sacra 37. A nivel local pueden consultar: Parramon Doll, Antonio Maria. 1966-1968. «Los boletines eclesiásticos leridanos. Tres publicaciones centenarias», Ilerda XXIX: 299-310.

Hispania Sacra, LXVII

136, julio-diciembre 2015, 673-715 ISSN: 0018-215X, doi: 10.3989/hs.2015.020 
cuenta, como el eclesiástico, el administrativo y el disciplinar, aspecto este último directamente relacionado con el control que ejercía el prelado sobre los fieles. ${ }^{51}$ La realizada por Cirilo Úriz a lo largo de 1852 y 1853 se centró en los arciprestazgos de Lleida y Roda. Teniendo en cuenta la correspondencia entre el prelado y los curas de algunas parroquias podemos plantearnos afirmar la existencia de una claro déficit de respeto y seguimiento del clero hacia los postulados eclesiásticos. Las fuentes documentales del año 1851 consultadas procedentes del archivo diocesano de Lleida reflejan las tres prioridades del pastor diocesano. En primer lugar, Cirilo Úriz creyó necesario que los curas realizaran un minucioso censo de todos los niños existentes en cada distrito parroquial con el fin de poder formarlos y recibir el sacramento de la confirmación. Afirmaba Úriz relativo a este tema: «Deseando por una parte que en la administración del Santo Sacramento de la confirmación se observe todo cuanto se previene en el Pontifical Romano, y á fin de evitar por otra el desorden, confusión y repetición de dicho Sacramento, ordeno: Primero- los Párrocos ó Ecónomos formarán de antemano una lista de las personas de su parroquia, que no hubiesen recibido este Sacramento (...) Segundo- rectificadas las listas se dedicará el Párroco a enseñar a los adultos todo lo perteneciente al Sacramento de la Confirmación, sobre el cual y sobre lo demás de la doctrina cristiana serán examinados, si lo creemos necesario, por la persona que designaremos a este fin...». ${ }^{52}$ En segundo lugar, anunciaba la obligatoriedad de llevar diariamente la vestimenta correcta según la época litúrgica del año. Sus frases eran taxativas, no dejaban la puerta abierta a ninguna interpretación ambigua. La desobediencia seria duramente castigada mediante sanciones y multas llegando incluso a la suspensión laboral y económica de los rectores: «En la carta, que al principio del Pontificado, escribimos para nuestro amado Clero, le exhortamos al uso diario del traje clerical correspondiente á su estado. Los sagrados cánones le imponen terminantemente esta obligación, á la que faltan

\footnotetext{
${ }^{51}$ Las visitas no hacen sino fan sino que traducir les relaciones de poder establecidas un organismo puramente jerárquico. Aunque revestidas de elementos pastorales e incluso paternalistas, no tenemos que olvidar el trasfondo de control que aportan esta tipología de documentación. Su análisis nos puede permitir establecer relevantes aportaciones, como el carácter geográfico de la diócesis, la organización eclesiástica (nombramiento de ministros eclesiásticos, licencias para la administración de sacramentos), la disciplina interna, (tanto des de un punto de vista material como espiritual) y la ejecución del ministerio pastoral (promoción de misiones y predicaciones, administración de los sacramentos de la confirmación, estímulo de la enseñanza de la doctrina cristiana). Más información de estas cuestiones en: Cortes, Antonio Luis y Lopez, Miguel Luis. 1996. «Las visitas ad limina y las visitas pastorales como instrumento de control (la diócesis de Granada en la segunda mitad del siglo XVIII)», en Juan Luis Castellanos (ed.), Sociedad, Administración y Poder en la España del Antiguo Régimen: 287-313 Granada: Servicio de Publicaciones de la Universidad de Granada y más recientemente: Joaquim Puigvert (ed.). 2003. Les Visites pastorals: dels orígens medievals a l'època contemporània: Girona: CCG edicions.

${ }^{52}$ Arxiu Diocesà de Lleida (archivo diocesano de Lleida, a partir de ahora ADL), Sección Úriz, Correspondencia. Circular impresa de Pedro Cirilo, Obispo de Lérida, dirigida a los Reverendos Curas Párrocos. Lérida, 4 mayo de 1851.
} 
los Eclesiásticos, que usan vestidos indecentes y seculares ó por la forma ó por el color. También faltan á ella con mayor culpabilidad aquellos Eclesiásticos que en el ejercicio de las funciones de su ministerio no visten habito negro talar. (...) Procederemos contra los inobedientes á lo que hubiese lugar hasta imponerles la pena de suspensión, si desoyen tenazmente nuestros avisos...». ${ }^{53}$ En tercero y último lugar, establecía la obligatoriedad de residir en los propios centros parroquiales y en las casas rectorales. Sus palabras también eran incuestionables: «Es muy clara y terminante la obligación de los Párrocos y Regentes ó Ecónomos á residir en sus Iglesias Parroquiales... No disimularemos falta alguna en esta parte, lo que servirá á Nuestro gobierno, así como también que no concederemos licencia de la Parroquia el que no exprese y justifique en el memorial el motivo ó causa porque para ausentarse, y la persona a quien en su caso encomendará el cuidado de su feligresía...». ${ }^{54}$

Las órdenes anunciadas por el prelado a partir de entonces en el Boletín Eclesiástico del Obispado seguirían una tónica algo parecida. Ellos se convertirían en eslabones continuadores de la tarea iniciada el 1851. Conforme observará el lector, todos ellos constituirán el epicentro conceptual de la praxis eclesiástica.

Uno de los primeros anuncios dados por Cirilo Úriz a los curas, durante el año 1853, era de tipo prohibitiva. Se había anulado la ley que les permitía recaudar limosnas para ermitas y santuarios sin el permiso pertinente. Por esto los avisó que vigilaran a los ermitaños que pidieran dinero sin el permiso de los vicarios generales: «dándonos aviso de cualquier abuso que se hubiere introducido en esta parte para proveer de remedio...». ${ }^{55}$ Además ordenaba que se le informara del número de parroquias en estado ruinoso y que, en caso afirmativo, las cerraran impidiendo posibles profanaciones. Estas órdenes, de cariz inmediato, serían complementadas con la incorporación, en primer lugar dentro el Boletín Eclesiástico, de numerosas instrucciones y artículos dedicados a la instrucción del clero en varias materias, como la preparación del sacerdocio y su ingreso en el altar, ${ }^{56}$ la liturgia, los buenos modales ${ }^{57}$ así como la instrucción

${ }^{53}$ ADL, Santa Visita de Roda, 29 julio de 1851. Circular de Pedro Cirilo, Obispo de Lérida.

${ }^{54}$ ADL, Santa Visita de Roda, 29 julio de 1851. Circular de Pedro Cirilo, Obispo de Lérida.

${ }^{55}$ BEOL, núm. 6, 19 julio 1853,41 .

${ }^{56}$ BEOL, núm. 9, 23 agosto $1853,68-70$.

${ }^{57}$ BEOL, núm. 11, 30 septiembre 1853, 84-88. Estas prerrogativas se acompañaron de la publicación el año 1856 de una carta pastoral. En ella Úriz centraba su discurso en la importancia de mejorar los buenos modales en la vida y la acción de los rectores. Para él eran incompatibles la predicación con los malos hábitos y acciones. Proponía tres métodos para mejorarla: ser beneficioso con los donativos, involucrarse con los más pobres y relacionarse correctamente con la feligresía. Úriz, Pedro Cirilo. 1856. Prevenciones para el ejercicio de la cura práctica espiritual: Lérida, Imprenta Corominas. En la misma tesitura publicó una obra de su tío Úriz y Lasaga, Javier. 1856. Carta Pastoral. Prevenciones para el ejercicio de la cura práctica espiritual, que escribió para los párrocos el Excmo. y que reimprime con su conocimiento y asenso del Ilmo. Sr Pedro Cirilo Úriz Prelado de Lérida: Lérida: Imprenta Mariana.

Hispania Sacra, LXVII

136, julio-diciembre 2015, 673-715 ISSN: 0018-215X, doi: 10.3989/hs.2015.020 
moral y religiosa. ${ }^{58}$ La inmediatez cronológica con la cual aparecen estas órdenes, el año 1853, denotaban la relevancia que Úriz dedicó a la revitalización formal y moral de sus sacerdotes y el papel de los Boletines como nuevo mecanismo de transmisión ideológica y de comunicación jerárquica de las prerrogativas diocesanas. Empleando este fondo documental, podemos darnos cuenta de la situación real de los rectores y de su grado de desobediencia. El número, temática e importancia de los dictámenes del prelado ofrecían toda una amplia variedad de los problemas existentes y la búsqueda de soluciones.

Anunciaba, en segundo lugar, que había apreciado como en muchas parroquias se habían perdido los libros de las constituciones sinodales y que, por lo tanto, los curas no sabían qué debían hacer. Como que no podía reimprimirlas, Úriz acordaba que se copiaran del Boletín aquellas que podían resultar esenciales. Entre las más importantes destacaban: «que los curas residan de día y noche en sus parroquias o abadias, bajo pena de 50 libras jaqueses de multa, que se cuiden del mantenimiento y reparación de sus casas mediante la dotación recibida por el culto, habrán de dejar habitables los recintos cuando marchen a otra parroquia o abadía y que se notifique al arcipreste correspondiente el posible dinero o problemas que ello pudiera suscitar" ${ }^{59}$

El tercer campo de actuación donde Úriz centró su atención fue en el control moral de las lecturas de curas y fieles. Una circular publicada a finales de 1853 avisaba de la necesidad de vigilar la difusión de libros, folletines, novelas y otros escritos irreligiosos e inmorales. Él lo sabía porque lo había visto y comprobado en la visita, y les recuerda que están prohibidos también por la Reina. ${ }^{60}$

En el cuarto campo atacaba directamente la carencia de instrucción de muchos curas en los deberes de la religión y de su respectivo estado u oficio. Otros, además, ignoraban incluso el catecismo de la doctrina cristiana. Por esto, pide a los curas que hagan un esfuerzo extra para que expliquen en cada sermón un punto de doctrina cristiana y para que expongan el Evangelio. ${ }^{61}$ Decía Úriz: «Hemos de corregir semejantes abusos y desórdenes; y no debiendo permitir que se continúen por más tiempo». ${ }^{62}$ Las misas no se ejecutaban, los sufragios, obras pies, testamentos y fundaciones, ni se hacían ni los curas cobraban el dinero para su celebración. En la búsqueda de soluciones, ordenó que a partir de entonces volviera la figura del Colector en las Visitas, que sería el encargado de controlar la ejecución de las competencias de carácter económico que todavía mantenían (capellanías, vínculos, cofradías y otras fundaciones), y avisó al

\footnotetext{
${ }^{58}$ BEOL, núm. 12,15 octubre $1853,90-94$.

${ }^{59}$ BEOL, núm. 11,30 septiembre $1853,83-84$.

${ }^{60}$ BEOL, núm. 13, 2 noviembre 1853, 97-98.

${ }^{61}$ BEOL, núm. 14,16 noviembre $1853,105-106$.

${ }^{62}$ BEOL, núm. 5,9 julio $1853,34-35$.
} 
Fiscal Eclesiástico, José Millá, que también ejercía como rector del Seminario Conciliar, para que iniciara investigaciones relacionadas con posibles irregularidades y emprendiera las consecuentes acciones legales.

Por otra parte, con la idea de potenciar la devoción entre los fieles, ordenó que en todas las iglesias parroquiales se llevara a término la celebración de la misa conventual, con la obligatoria asistencia de los Diáconos y Subdiáconos parroquiales. «Para que nadie presente ignorancia» ${ }^{63}$ afirmaba que también estarían presentes los rectores que no celebraran misa todos los días de precepto pues, hasta aquellos momentos, era una de las faltas más comunes. No podemos dejar de banda el episodio relatado por Ramiro Viola ${ }^{64}$ que enfrentó al obispo ilerdense con el clero regular y que explican, parcialmente, la nula incorporación de conventos a la diócesis durante su mandato. Pedro Cirilo Úriz, siguiendo las normas concordatorias en materia de órdenes religiosas, envió el 1852 al Ministerio de Gracia y Justicia una relación de los conventos de religiosas existentes en la diócesis. En él, las referencias a un reciente fundado convento en les Borges Blanques con el nombre de Carmelitas de la Caridad eran inexistentes. El Ministerio, extrañado por el desconocimiento de un prelado que hacía más de dos años que atendía el obispado, le pidió más información. Todo ello indica la pueril actuación de Úriz en un asunto tan importante como este. A partir de este momento decidió no permitir la incorporación de ninguna nueva orden regular femenina. La plasmación de tal radical medida tendría dos consecuencias. En primer término, la prohibición y disolución de la Escuela de la Virtud. A pesar del desconocimiento que el prelado tenía sobre la figura del padre Palau, fundador de la orden, y el hecho que ya se habían instalado en Lleida (concretamente a la parroquia de Santo Andreu) y Aitona (población originaria de Palau), la orden fue irrevocable. La escuela intentó por múltiples caminos anularla pero Úriz, sin aminorar nada su opción, recurrió al gobernador civil, Manuel Estremera, para que ejecutara la disolución. ${ }^{65}$ Esta sería la única vez que lo veremos adoptando medidas tan radicales y drásticas. En segundo término, la intransigente postura incidió negativamente en la instalación de nuevos centros monásticos femeninos. La tendencia viraría durante los años sesenta gracias, entre otros elementos, al contexto histórico y la nueva línea pastoral seguida por el obispo Puigllat. Llegaría a su máximo apogeo a finales de siglo bajo los auspicios del obispo Messeguer.

\footnotetext{
${ }^{63}$ BEOL, núm. 5, 9 julio 1853, 34-35.

${ }^{64}$ Viola, Ramiro. 1984. Historia de la Congregación de Carmelitas Misioneras Teresianas: Roma: Imprenta Monte Carmelo.

${ }^{65}$ Esta actuación dista mucho de la que realizó posteriormente en Pamplona. En aquella ocasión se mostró inflexible ante el intento de anulación de la compañía de Jesús víctima mártir, según Úriz, de la revolución: Revuelta Perez, Manuel. 1984. La Compañía de Jesús en la España contemporánea, T. I: 136 Madrid: Universidad Pontificia Comillas.
} 
La legitimación ideológica y administrativa del régimen moderado: aspectos ideológicos.

Realizadas varias actividades de reorganización, reestructuración y modernización del obispado, siguiendo los postulados del recién firmado Concordato de 1851, Pedro Cirilo Úriz y Labayru dedicaría parte de los últimos años en la diócesis leridana a la reflexión teórica sobre el papel de la iglesia española en relación a los nuevos tiempos. Esta misma tarea se prolongaría posteriormente en la sede pamplonica. A partir de 1859 empezó a publicar sus primeros tratados conceptuales. Los temas que desarrolló son muchos, pero creemos que pueden agruparse en tres grandes grupos: apoyo incondicional a la monarquía -en unos tiempos especialmente difíciles para España- defensa a ultranza del poder temporal del Papa y, en último término, el intento de conjugar progreso y civilización moderna con el inmovilismo social, político y económico de la iglesia. Pasamos a analizarlas:

\section{Apoyo a la monarquía:}

Anclado en algunas ideas eminentemente de cariz integrista fue un claro defensor de la nación española y de la monarquía como institución. Generalmente se posicionaría junto a la reina y la monarquía como institución aun cuando algunas decisiones aceptadas por esta -que consideraba como perniciosos desvíos- no gustaron al prelado iruñés. En los diversos discursos escritos por Úriz será constante presentar España como un todo unitario defensor de las pretéritas tradiciones cristianas frente un mundo lleno de codicia y mal representado por los mahometanos. La ocasión perfecta para el desarrollo de este ideario se produciría en las acciones bélicas entre España y Marruecos a mediados del siglo XIX. Fracasados los intentos negociadores entre ambas partes con los que se intentaba solventar el enfrentamiento, se inició un conflicto armado de importantes repercusiones. Úriz se mostró impecable en su visión del mismo y su incondicional apoyo a las posturas seguidas por la reina. Siguiendo los parámetros de una amplia corriente del catolicismo tradicional hispánico, Úriz y Labayru, escribiría una primera carta dónde la utilización de un discurso martirial dejaba entrever la defensa de una fe triunfante aunque no peregrina. ${ }^{66}$ En la citada carta se muestra partícipe de la declaración de la guerra como último, pero necesario, método para frenar a los seguidores del Corán. La tradicional tríada relacional entre Religión, Trono y Patria surgía una vez más como elementos imprescindibles para la defensa

${ }^{66}$ Úriz, Pedro Cirilo. 1859. Exhortación Pastoral que el Ilmo Pedro Cirilo Úriz Obispo de Lérida dirige a sus diocesanos con motivo de la alocución pronunciada por S.S. Pío Papa IX en el Consistorio de 26 de setiembre de 1859: Lérida: Imprenta Mariana. 
cristiana del país. Los pretéritos forjadores de la España católica -los Pelayos, Hernán Cortés y Cisneros- retomaban su esplendor. Ellos habían convertido el país en uno de los grandes baluartes del catolicismo mundial. Siguiendo estos patrones los soldados, convertidos por Úriz en cristianos defensores del catolicismo, encontrarían en sus acciones su salvación: «Trabajando de consumo, la pericia de nuestros Generales y el valor de nuestros soldados alcanzarán la victoria, que no puede ser dudosa, máxime si para conseguirla les ayudamos con las armas de otro temple, si mientras ellos pelean como los Cruzados, nosotros pedimos y les alcanzamos los auxilios del que á todos nos redimió en la cruz. Oremos, pues, con fe viva, con humildad y confianza, y obtendremos lo que tanto anhelamos: empezemos hoy á interesar al Dios de las batallas a favor de nuestros denodados generales, oficiales y soldados».

Según Úriz, la guerra sólo podía ganarse de una manera: con las plegarias y las rogativas públicas de todo el país a favor de los soldados. Este discurso, basado en el miedo, será una de las constantes del prelado. La conjunción de todos los elementos descritos, se materializaría en la movilización de los fieles. Era preciso, por una parte, la asistencia a las misas diarias y, por otra parte, el seguimiento de las rogativas públicas alentadas desde los diversos obispados y en muchas ocasiones por los Gobernadores Civiles. Acontecimientos políticos como este serían utilizados como la excusa perfecta para la ampliación de los efectos recristianizadores que Úriz pretendía establecer en toda la diócesis. Todo y los problemas existentes, emplearía el nacionalismo español como movilizador social apoyando a la monarquía, pero también como muestra del teórico creciente poder del catolicismo español.

\section{Adhesión a los postulados de Pío IX:}

Úriz dedicó gran parte de su reflexión teórica a la defensa del poder temporal del Papado y a la protesta enérgica y formal contra los acontecimientos anticlericales desarrollados en la Italia de mediados del siglo XIX. Punto constante de sus discursos serían los posicionamientos defensivos ante la cohesión de las fuerzas revolucionarias. En algunas ocasiones aprovechó la publicación de encíclicas pastorales y alocuciones papales para extrapolar los graves acontecimientos italianos comparándolos con la situación vivida en España. En ambos casos, los paralelismos serían más que convergentes. El enfrentamiento entre progresistas y la iglesia es presentado como una lucha dónde sólo es posible la victoria de uno de los dos pretendientes. No existe espacio suficiente para pactos intermedios. El estado se había separado de la religión y se había presentado como verdadero portador del cristianismo. Los resultados, pero, habían sido del todo negativos. Uriz manifestaba abiertamente: «santuarios despojados, asilos consagrados hace poco al pudor y á la inocencia, blancos ahora de la más 
cruel violación: altares demolidos, templos profanados, Príncipes de la Iglesia arrancados de sus diócesis, sin consideración alguna á su jerarquía, á su ciencia, á su virtud ni á la orfandad de sus ovejas?». ${ }^{67} \mathrm{El}$ punto de enfrentamiento fue, según Úriz, la pérdida del poder que históricamente había ostentado la iglesia católica en España y el creciente anticlericalismo.

Según nuestra opinión los problemas expuestos por el prelado, extrapolables a gran parte de la iglesia española decimonónica, eran esencialmente dos. En primer lugar, el radicalismo postulado mayoritariamente por la alta jerarquía eclesiástica. Cualquier temática relacionada con la iglesia tenía que ser blanca o negra. Se estaba con ella o contra ella. El catolicismo había sido relegado de su pretérito punto privilegiado en la sociedad y la única solución posible era el regreso al ideario del Antiguo Régimen. En segundo lugar, encontraríamos la carencia de iniciativas y alternativas que posibilitaran el acomodo de la Iglesia a los nuevos postulados políticos, económicos, sociales y culturales surgidos del liberalismo. La búsqueda de Jaume Balmes de posiciones intermedias nunca obtuvieron una respuesta masiva y afirmativa por parte del radicalismo religioso.

En los textos escritos por Pedro Cirilo Úriz en algunas ocasiones podemos apreciar un tímido intento de reclamar la búsqueda de nuevas soluciones. Él proponía un acatamiento incondicional a la figura de la reina y al acuerdo concordatorio. Un régimen católico pleno debería desarrollar y mejorar el Concordado de 1851 beneficiando la posición del catolicismo. Ahora bien, Úriz no se define en el momento crucial de establecer las contraprestaciones y las concesiones que la Iglesia debería llevar a término. Todo lo contrario, en este punto retoma el antiguo discurso basado en la defensa a ultranza del catolicismo, el inmovilismo y la defensa de los antiguos privilegios.

En Italia los territorios papales ubicados en la zona de Bolonia y Rávena, a finales de los años sesenta, cada vez eran menores. La dirección y el gobierno que la Santa Sede había dirigido durante largos siglos sobre gran parte de los territorios que, posteriormente, conformarían la Italia unificada eran conquistados por los movimientos nacionalistas emancipadores. La pérdida del poder temporal de Pío IX había ocasionado el origen de una creciente espiral de protestas. ${ }^{68} \mathrm{El}$

${ }^{67}$ Úriz, Pedro Cirilo. 1861. Exhortación Pastoral que el Ilmo Pedro Cirilo Úriz Obispo de Lérida dirige a sus diocesanos con motivo de la alocución pronunciada por S.S. Pío Papa IX en el Consistorio de 30 de setiembre de 1861: 4 Tarragona: Imprenta Mariana.

${ }^{68}$ Úriz publicaría el año 1859 diversos textos donde exponía públicamente sus quejas ante este acontecimiento. Hemos podido consultarlos gracias a que los recompiló posteriormente: «Exposición del Sr. Úriz y Labayru, obispo de Lérida», Boletín Oficial del Obispado de Pamplona: Tomo VII: 1870, 293 y «Pastoral del obispo de Lérida», Boletin Oficial del Obispado de Pamplona: Tomo VII: 1870, 294-300. Años más tarde, en su mandato episcopal en Pamplona, publicaría «Exposición que el Excmo. e Ilmo. Sr. Obispo de Pamplona ha dirigido a S.M. la Reina contra el reconocimiento del pretendido reino de Italia», Boletín Oficial del Obispado de Pamplona: Tomo II: 1865, 193. 
Papado, por su parte, tampoco quiso aceptar en aquellos momentos el triunfo de nuevos movimientos en Europa. Las posiciones radicales triunfaban y no había lugar para el diálogo. La iglesia apreció todos estos hechos como un ataque directo a su privilegiada posición social: «se han declarado en guerra abierta contra la Iglesia católica persiguiendo sin tregua á sus ministros» ${ }^{69}$ Esta misma situación la extrapolaba Uriz para el caso español. El prelado de origen navarro protestaría por la pérdida de sus tradicionales poderes monopolistas, especialmente el de los medios de comunicación y los culturales. ${ }^{70}$ Decía Úriz relacionado con ello: «se han declarado en guerra contra la Iglesia católica, mofándose de sus sacramentos, ritos y ceremonias con ridículas caricaturas en los teatros, plazas y templos, y difundiendo con profusión por todas partes libros, novelas y folletos salpicados de herejías, errores y falsas máximas de inmoralidad». ${ }^{71} \mathrm{La}$ única posible solución era, entonces rogar y esperar. Mientras tanto, Úriz publicaba las diversas alocuciones papales traducidas al castellano como prueba ecuánime de los acontecimientos acaecidos en Italia y como método para intensificar la búsqueda de soluciones basadas en la movilización de los fieles.

\section{Posicionamientos ante el progresismo y la civilización moderna:}

Entre los textos más interesantes de Úriz se encuentran los publicados en los últimos años de su estancia en Lleida en los que habla y se cuestiona las relaciones entre el progresismo político, los avances tecnológicos y la iglesia católica. ¿Qué papel debía jugar la última en la nueva sociedad? ¿Podría y debía adecuarse a los nuevos tiempos o era necesario seguir postulados totalmente contrarios? A estas y otras cuestiones intentó dar respuesta en tres extensos textos publicados los años 1860 y 1861. En el primero de ellos aprovechó la publicación de la encíclica del Papa para intercalar su particular visión y posicionamiento ante las controvertidas nociones de civilización moderna, libertad y progreso. Se trata de un extenso discurso donde también reflexiona sobre el origen del poder eclesiástico. Generalmente toma un posicionamiento defensivo ante las novedades coyunturales. La iglesia se encontraba en un momento delicado, pues la conjugación de elementos anticlericales había incidido en agravar la crisis del catolicismo español y Papal mediante la ampliación de las libertades y la reducción del poder territorial. Con la publicación de las encíclicas, Úriz demostraba su adhesión a los postulados jerárquicos e informaba a

\footnotetext{
${ }^{69}$ Úriz, Pedro Cirilo. 1859. Exhortación Pastoral que el Ilmo Pedro Cirilo Úriz Obispo de Lérida dirige a sus diocesanos con motivo de la alocución pronunciada por S.S. Pío Papa IX en el Consistorio de 26 de setiembre de 1859: 1 Lérida: Imprenta Mariana.

${ }^{70}$ Úriz, Pedro Cirilo. 1859: 1-2.

${ }^{71}$ Úriz, Pedro Cirilo. 1859: 2.
} 
los diocesanas sobre la generalización de las acciones de los revolucionarios. La defensa de la soberanía temporal del Papado fue uno de los centros de la lucha contra el ideario liberal. Especialmente duro se mostró ante el intento de reducción del poder temporal de Pío IX en Italia. Según Úriz, los acontecimientos provocados por los revolucionarios eran permitidos por las propias fuerzas divinas como método para intensificar la interrelación entre el pastor y sus ovejas. Este discurso únicamente pretendía agravar el sentimiento de culpabilidad entre los fieles. La búsqueda de soluciones se encontraba una vez más en acabar con la indiferencia mostrada por algunos católicos y con la movilización de los fieles..$^{72}$

Pasamos ahora a analizar el segundo de los escritos. El catolicismo español y europeo, según Úriz, había sido atacado por los liberales y progresistas por ir en contra de la sociedad humana al no aceptar los adelantos técnicos. El prelado defendía todo el contrario. La Religión había modernizado la sociedad alejándola del paganismo. Ahora, la jerarquía eclesiástica era un puntal más promovedora de la civilización. La iglesia no se oponía a los adelantos y al desarrollo tecnológico, artístico e industrial del momento. Al contrario: «aprueba y anima (...) todo cuanto se útil al progreso ordenado en las ciencias, en la industria y en las artes; todo cuanto propende á aliviar el peso de los sufrimientos inevitables en esta tierra de peregrinación para la patria celestial...». ${ }^{73}$ Únicamente rechazaba aquellos elementos que podían modificar sus privilegios y poder social. Según su personal cosmovisión, era posible la convivencia del progreso tecnológico con los principios de moralidad y de orden social de los católicos. Por lo tanto en este campo no presentaba un posicionamiento tangencial, integrista, radical ni antigubernamental. Propuso lo que, en cierto modo, podía convertirse en un nuevo modelo social dónde se alternarían el progreso económico y tecnológico con el inmovilismo político, social y religioso. El entendimiento era necesario. Sería beneficioso para toda la sociedad, al menos para todos aquellos que se aliaran favoreciendo el sistema descrito. ¿Quiénes podrían ser estos? Desgraciadamente esta información nunca aparecerá en los textos analizados. Llegados a este punto podemos afirmar que su análisis toma otras riendas. Era consciente de la creciente complejidad de la España decimonónica. Algunas políticas y medidas estatales habían perjudicado seriamente los fundamentos religiosos del país alimentando el paganismo y el anticlericalismo. Era la hora de actuar. Era la ocasión idónea para ir todos a una. Las fisuras eran cosa del

\footnotetext{
${ }^{72}$ Úriz, Pedro Cirilo. 1860. Circular del Ilustrísimo Señor Obispo de Lérida Al clero y pueblo de su diócesis del Arcipestrazgo de Ager y Abadiado de la O, comunicándoles la encíclica de su Santidad de 19 de enero último: Lérida: Imprenta Mariana.

${ }^{73}$ Úriz, Pedro Cirilo. 1861. Exhortación Pastoral que el Ilustrísimo Pedro Cirilo Úriz Obispo de Lérida dirige a sus diocesanos con motivo de la alocución pronunciada por S.S. Pío Papa IX en el Consistorio de 18 de marzo de 1861: 7 Tarragona: Imprenta Mariana.
} 
pasado. El episcopado debía presentarse a la sociedad caracterizándose por la unidad católica. Había que mostrar una adhesión incondicional a Pío IX y sus mandatos. Con la oración de todos los cristianos: «todos los pastores, íntimamente unidos en la aflicción cono su respetable jefe, participarán de su misma alegría, cuando vuelvan días tranquilos para la Iglesia y la sociedad». ${ }^{74}$

El tercer discurso de Úriz parte de unos postulados, sigue un discurso paralelo y llega a unas conclusiones equiparables a las descritas hasta el momento. Según su punto de vista, Pío IX no condenaba el progreso, sino que siempre se encontraba dispuesto a protegerlo. El Papa había potenciado las artes contemporáneas exponiéndolas en sus salas vaticanas, había aceptado y aplaudido varios inventos, como la fotografía, los telégrafos eléctricos, el vapor y el ferrocarril. Además los había potenciado invirtiendo y apostando para su pleno desarrollo.

Úriz presentaba un modelo de sociedad alternativo al del XIX, con unas características cercanas a las de los primeros tiempos del cristianismo. Éste se basaba en el seguimiento incondicional de los preceptos papales, en la defensa de la moral cristiana y en el inmovilismo de las estructuras preexistentes. Era precisamente este sistema el que históricamente había posibilitado que los pueblos bárbaros abandonaran su paganismo. A partir de este punto, el discurso de Úriz se basa en intentar demostrar, mediante ejemplificaciones históricas, como Roma se había convertido en la capital de la cristiandad y la civilización europea y mundial. Por ello la pérdida de los territorios papales era vista por Úriz con cierta resignación. La situación no era nueva.

Varias invasiones ya habían hecho sufrir pretéritamente una situación paralela. Si antes se había podido resistir, lo mismo podría hacerse ahora. ¿Qué soluciones presenta Úriz delante de toda esta problemática? En primer lugar, el sector perjudicado no es el eclesiástico, sino el revolucionario. Se cuestiona Úriz: «¿Qué quiere, pues, la revolución cuando exige á Pío IX el que se reconcilie cono la civilización moderna? Quiere un imposible; quiere que el grande Pontífice sancione el crimen, apruebe la usurpación, capitule con el robo, transija con la iniquidad... en una palabra: quiere hacerle su cómplice en los sacrílegos atentados que está cometiendo en Italia...». ${ }^{75}$ Aquí se encuentra el centro de la cuestión. La reacción de la iglesia se inicia cuando son cuestionados sus privilegios y cuando estos son alienados. ¿Cuál es la solución? Una vez más Úriz no se atreve a presentar una alternativa. Se debe seguir e imitar los ejemplos pontificios, es decir, esperar. Mientras el tiempo pasa, es necesaria la colaboración de los cristianos mediante la oración, la obtención de limosnas y,

\footnotetext{
${ }^{74}$ Úriz, Pedro Cirilo. 1861: 9.

${ }^{75}$ Úriz, Pedro Cirilo. 1861: 31.
} 
en último lugar, la movilización de los cristianos. Es el momento de demostrar la unidad del catolicismo, de aparecer cohesionados, sin fisuras y apostar decididamente por las prerrogativas papales. A partir de este punto será posible «la acción y vida de todos los miembros de la Iglesia». Nos habla de las causas de su descontento: «embarazando la acción del legislador, del juez, del consultor, del jefe del catolicismo, se logra introducir la perturbación en el seno de la Iglesia. Ved aquí lo secreto de todos los tiros que se le dirigen, y la causa de nuestro legítimo interés por él». ${ }^{76}$ Se ha tocado y perjudicado la esencia del cristianismo, es decir, el poder temporal y los mecanismos de control social, político, ideológico y cultural de la sociedad. Si se reduce el poder temporal del Papa, podrá a largo plazo presentarlo como un esclavo. ¿Es posible, se cuestiona Úriz, que el Papa pueda continuar mandando si pierde sus territorios en Italia? La respuesta era clara: «El ánimo se aflige y abate al solo pensar en las consecuencias de semejante situación. El Pontífice podría verse obligado á comprar su independencia al precio del martirio». ${ }^{77}$ Tampoco cabía una situación intermedia. Si la Iglesia cede, cualquier personaje podría hacer exactamente lo mismo. Es imprescindible resistir, defender heroicamente unos territorios que han sido cedidos por el más allá, hace falta mantenerlos cueste lo que cueste. Si se pierden los territorios, se habrán acabado los ingresos económicos y la independencia respeto del Estado. Es por lo tanto del todo preciso y necesario las limosnas y donativos de los fieles. Tras todo este discurso, Úriz pone en funcionamiento la maquinaria jerárquica y la estructura administrativa del obispado para la recaudación de dinero. ${ }^{78}$ Esta se llevaría a término mediante los rectores y los arciprestes que conducirían las cantidades económicas al obispado. Para intensificar esta obligación, propuso la creación de juntas parroquiales formadas por laicos designados por los rectores para que articularan y potenciaran el buen desarrollo de la recolecta.

En fin, aquello que Pedro Cirilo Úriz intentaba realizar era buscar el papel o la reorientación que la iglesia debía tomar y tener en el nuevo panorama político español. Era consciente de la debilidad del catolicismo frente el creciente poder y articulación del estado nacional. Por lo tanto, la única solución posible era pactar. Ahora bien, esto no suponía seguir los postulados y las teorías publicadas por Jaume Balmes, sino que su pretensión se basaba en defender y acatar incondicionalmente la institución monárquica y los diversos puntos pactados en el Concordato de 1851. Con esta postura se hacían patentes dos cuestiones capitales. En primer lugar, desmontaba la trama conspirativa y violenta formulada por

\footnotetext{
${ }^{76}$ Úriz, Pedro Cirilo. 1861: 17.

${ }^{77}$ Úriz, Pedro Cirilo. 1861: 19.

${ }^{78}$ Todo este proceso puede seguirse en la obra de: Úriz, Pedro Cirilo. 1860. Exhortación Pastoral que el Ilustrísimo Pedro Cirilo Úriz Obispo de Lérida dirige a sus diocesanos con motivo del Empréstito Pontificio: Tarragona: Imprenta Mariana.
} 
el carlismo y a su vez se alejaba de los sectores más intransigentes y radicales del catolicismo español; en segundo término, se aseguraba la imposibilidad de perder más privilegios. Era posible la convivencia y el progreso con los principios de moralidad y de orden social de los católicos. En otras palabras, Pedro Cirilo Úriz dejaba entrever y proponía un nuevo modelo de estado basado en el entendimiento y comprensión entre los avances y las novedades económicas y tecnológicas con el inmovilismo político, social y religioso. Así confluían los intereses de los dos sectores interesados. Los moderados recibían el apoyo de gran parte del clero nacional como institución. Por su parte la iglesia frenaba las aspiraciones desamortizadoras y alienables del gobierno y, por otra, dejaba la puerta abierta a potenciales mejoras e, incluso, al regreso de parte de sus antiguos privilegios.

\section{El traslado de Úriz a Navarra:}

Creyendo que pasaría en la capital del poniente catalán toda su vida, Úriz se hizo construir una capilla en la Catedral Nueva ${ }^{79}$ Pero ante la sorpresa de todos la reina lo nombraba el año 1861 obispo de Navarra sustituyendo al nombrado Severo Leonardo Andriani ${ }^{80}$ Su traslado se convirtió en un acto muy emotivo. Así lo reflejan algunas de la fuentes eclesiásticas consultadas al afirmar: «El prelado se despidió con una tierna y afectuosa carta pastoral de sus amados diocesanos del Obispado de Lérida, y estos a la despedida y en los años siguientes le dieron de mil maneras pruebas inequívocas de aprecio y del más fino amor filial, mientras el que durante diez años fue su Obispo conservó de ellos hasta la muerte la más grata memoria, de que hacía frecuentemente conmemoración con la mayor estimación y paternal afecto». ${ }^{81}$ Tres años antes de su traslado, regaló a su amada iglesia Catedral de Lérida varias alhajas de crecido valor.

Según el historiador José Manuel Cuenca Toribio, ${ }^{82}$ uno de los principales estudiosos del prelado, la monarquía isabelina trasladó a Úriz de Lleida

${ }^{79}$ Lleida es de las pocas sedes diocesanas con dos catedrales. La primera fue reconvertida en caserna militar cuando Felipe V conquistó la ciudad a principios del siglo XVIII.

${ }^{80}$ Archivo del Ministerio de Justicia (a partir de ahora AMJ), legajo 3949, núm. 11305. En este legajo se encuentra la documentación relativa al traslado de Úriz a Pamplona.

${ }^{81}$ BEOL, núm. 122, 30 agosto $1874,274$.

${ }^{82}$ Cuenca Toribio, José Manuel. 1976. Sociología de una élite de poder de España e Hispanoamérica Contemporánea: la jerarquía eclesiástica (1789-1965): Córdoba: Escudero. En la misma tesitura se manifestó unos años después en su obra: Cuenca Toribio, José Manuel. 1980. Sociedad y clero en la España del siglo XIX: Córdoba: 166-180 Córdoba: Monte de Piedad y Caja de Ahorros. También relacionado con la figura de Úriz en el obispado de Pamplona pueden consultar: Cuenca Toribio, José Manuel. 1969. «El pontificado Pamplonés de D. Pedro Cirilo Úriz y Labayru (1862-1870)», Hispania 
a Pamplona para contrarrestar con un obispo de ascendencia liberal el clima carlista de su región natal. Allí se dedicó al arreglo parroquial de la diócesis, materializada el año 1864, la publicación del Boletín Eclesiástico Oficial de la Diócesis de Navarra, la instauración de un nuevo arancel de derechos parroquiales y de fábrica y, sobre todo, a la reflexión y a la protesta ideológica del mal trato que, según él, sufría la jerarquía y el clero español. Buena muestra de esto lo constituyen sus adhesiones a las encíclicas Cuánta Cura y al Syllabus así como las enérgicas protestas contra las exigencias del Gobierno el año 1865, donde pidió a la Reina la necesidad de someter la monarquía y al estado a la voz del Vicario de Jesucristo en la tierra. La ocupación de Roma el año 1870 y la celebración del Concilio le condujeron hasta Roma. Allí fue nombrado por el Papa Pío IX Prelado Asistente al Sacro Solio Pontificio, uno de los cargos más relevantes en la jerarquía vaticana. La conjunción de todos estos elementos le supondrían la obtención de varios premios y condecoraciones, entre los cuales destacó la Gran Cruz de Isabel la Católica. Murió después de su regreso de Roma donde asistió al concilio Vaticano I. Su cuerpo descansa junto al sepulcro de su tío Javier Úriz en el panteón de la Barbazana de la santa iglesia de Pamplona. ${ }^{83}$ Sus bienes y rentas en Olite serian administrados por Manuel Mercader -canónigo de la catedral de Pamplona y buen colaborador de Úriz- y Diego Tirapu -párroco de la iglesia de San Pedro de Olite. ${ }^{84}$

Sacra XXII: 129-287 y del mismo autor 1979. «El pontificado pamplonés de Pedro Cirilo Úriz y Labayru (1862-1870)», Cuadernos de Investigación Histórica 3: 55-124.

${ }^{83}$ Úriz realizó su testamento el año 1866. En él pedía ser enterrado en la catedral de Pamplona y en caso de no ser posible entonces en San Pedro de Olite delante del altar de los Santos Juanes, con una losa que no sobresalga del suelo. Además dejaba dinero para realizar misa diaria en su honor en Olite los meses de abril y septiembre de cada año. Nombraba albaceas y cabezaleros a su hermano Hemeterio Úriz, a su primo Juan Úriz, al licenciado Francisco González arcipreste de la catedral y al doctor D. Manuel Mercader canónigo de la catedral. (Parece que en 1886 cuando se lleva adelante la testamentaría está solamente Mercader), Archivo Capitular de Pamplona, caja 1388, Carpeta 1, Testamento de Pedro Cirilo Úriz, 22 de noviembre de 1866.

${ }^{84}$ Actuarían como subcabezaleros el Deán, Penitenciario y Magistral de la catedral de Pamplona. Su función es administrar los bienes y rentas. A continuación resumimos los principales gastos realizados anualmente por el obispo Úriz en su tierra natal. Ello demuestra una vez mas su compromiso personal con la población que le vio nacer y crecer: Reparto albaceas, pago a diversos capellanes de Olite (al principio, 6 al final 1), estudiantes navarros beneficiados (entre 8 y 16), asignación al preceptor de latinidad de Olite, misas por capellanías y administrador de los bienes. En el siglo xx es habitual una aportación para el organista de San Pedro. Desde la llegada de las hermanas de la Caridad aporta 500 pts anuales, en Olite se ayuda varias veces al hospital y al párroco para niños pobres, limosna a las monjas de Santa Engracia (no se fija una donación concreta pero su número se repite anualmente), ayudas en limosna a obras pías e instituciones religiosas de Pamplona, como las Hermanitas de los pobres y la Sagrada Familia. Archivo Capitular de Pamplona, caja 3077, libro 240, Testamentaría del Excmo. E Ilmo. Sr. Doctor D. Pedro Cirilo Úriz y Labayru, obispo que fue de Pamplona. Este libro contiene y recoge las cuentas personales de Úriz entre los años 1886 y 1941. 


\section{Conclusiones}

Durante el Bienio Progresista Úriz demostró cual era realmente su pensamiento y su posicionamiento ante los acontecimientos y cambios políticos acontecidos en España durante la primera mitad del siglo XIX. Se mostró activamente partícipe y a favor de la monarquía y de la reina. Aún así luchó fervorosamente contra aquello que él consideraba ataques directos a la iglesia católica española, es decir, las leyes desamortizadores y algunos de los puntos y artículos incluidos en el Concordado de 1851. Protestó enérgicamente contra su aprobación y manifestó la necesidad de ir más allá y hacer del catolicismo una ley constitucional. Pedro Cirilo Úriz no fue un prelado liberal, pero tampoco se mostró extremadamente integrista. Se opuso al carlismo, aceptó la monarquía e incluso las reglas del juego político insertadas por el gobierno moderado. Pero se manifestó abiertamente contrario a los postulados de los progresistas. Se enfrentó con ellos en Lleida por varias cuestiones relacionadas especialmente con asuntos económicos, pero fue capaz de ayudar y pactar con las instituciones civiles en momentos de enfermedad y de tragedia. Cirilo Úriz no perseguía el enfrentamiento con el Estado. Era consciente del decreciente papel de la jerarquía eclesiástica en las esferas del poder y la toma de decisiones. La opción armada de los carlistas como aglutinadora y defensora de los católicos sólo había conducido a la fragmentación social y la muerte de muchos ciudadanos. Úriz perseguía la conjugación de la iglesia católica española con el Estado, una opción intermedia pactada que beneficiara ambas partes. Según sus postulados teóricos era preciso que el catolicismo aconteciera religión oficial y disfrutara de algunos de sus tradicionales privilegios a cambio de la aceptación de la monarquía isabelina, el gobierno moderado, la modernidad en el campo social, tecnológico e incluso cultural. Podía aceptar la modernización tecnológica del país y los cambios sociales pero no podía permitir ni aceptar ataques directos a la Iglesia, como la persecución de curas o la desaparición de su aparato económico. Por todo ello presentaba como axioma indiscutible la necesidad de volver a unir el estado con la Iglesia. Para Úriz el catolicismo había de jugar un papel primordial como representante y cohesionador del alma y la patria española. 
ANEJo 1:

Proposición de arreglo parroquial del arciprestazgo de Lleida remitido por Pedro Cirilo Úriz y Labayru, obispo de Lleida, al Ministerio de Gracia y Justicia de Madrid (1857):

\begin{tabular}{|c|c|c|c|c|c|c|c|}
\hline \multirow{2}{*}{ Población } & \multirow{2}{*}{ Habitantes } & \multirow{2}{*}{$\begin{array}{l}\text { Clasificación } \\
\text { Actual }\end{array}$} & \multirow{2}{*}{$\begin{array}{l}\text { Clasificac. } \\
\text { Arreglo }\end{array}$} & \multicolumn{2}{|c|}{ Dotación personal } & \multicolumn{2}{|c|}{ Asignación culto } \\
\hline & & & & Actual & Arreglo & Actual & Arreglo \\
\hline St. Pere & -------- & $2^{\circ}$ ascenso & Término & 5500 & 10000 & ------ & 2500 \\
\hline St. Llorenç & -------- & Término & Término & 7000 & 10000 & 7000 & 5000 \\
\hline St. Magdalena & -------- & 1er ascenso & Término & 4900 & 9000 & 4000 & 3000 \\
\hline St. Andreu & ------- & 1er ascenso & Término & 4900 & 9000 & 2500 & 2500 \\
\hline St. Joan & -------- & Término & Término & 7000 & 10000 & 7000 & 4000 \\
\hline Alamús & 238 & Entrada & $\mathrm{R}^{\mathrm{o}}$ de $1^{\mathrm{a}}$ & 3000 & 2800 & 900 & 1000 \\
\hline Albagés & 521 & 1er ascenso & Entrada & 4500 & 4000 & 900 & 1200 \\
\hline Albatarrech & 383 & 1er ascenso & Entrada & 3600 & 3500 & 900 & 1200 \\
\hline Alcanó & 381 & 1er ascenso & Entrada & 4900 & 3900 & 900 & 1200 \\
\hline Alcarras & 1.821 & Término & Ascenso & 7000 & 7500 & 1800 & 2000 \\
\hline Alcoletge & 893 & $2^{\circ}$ ascenso & Entrada & 4000 & 4000 & 1000 & 1200 \\
\hline Alfarras & 668 & $2^{\circ}$ ascenso & Entrada & 5500 & 5000 & 1000 & 1800 \\
\hline Alfés & 478 & $2^{\circ}$ ascenso & Entrada & 5500 & 4500 & 1000 & 1200 \\
\hline Alguayre & 2.233 & $2^{\circ}$ ascenso & Entrada & 5500 & 4500 & 1000 & 1200 \\
\hline Almacelles & 990 & $2^{\circ}$ ascenso & Ascenso & 5500 & 8000 & 2500 & 2200 \\
\hline Almatret & 1.138 & $2^{\circ}$ ascenso & Ascenso & 5500 & 5500 & 3000 & 1800 \\
\hline Almenar & 2.400 & 1er ascenso & Ascenso & 4500 & 8000 & 1000 & 2200 \\
\hline Artesa de Lleida & 574 & $2^{\circ}$ ascenso & Entrada & 5500 & 4000 & 1000 & 1200 \\
\hline Aspa & 580 & Entrada & Entrada & 3300 & 4000 & 1000 & 1200 \\
\hline Aytona & 1.980 & Término & Ascenso & 7000 & 7500 & 3000 & 2000 \\
\hline Belloc & 724 & $2^{\circ}$ ascenso & Entrada & 5500 & 4500 & 1200 & 1200 \\
\hline $\begin{array}{l}\text { Benavent del } \\
\text { Segrià }\end{array}$ & 688 & $2^{\circ}$ ascenso & Entrada & 5500 & 4500 & 1000 & 1200 \\
\hline $\begin{array}{l}\text { Borges } \\
\text { Blanques }\end{array}$ & 3.141 & Término & Término & 7000 & 9000 & 4000 & 4000 \\
\hline Bobera & 472 & Anejo & Entrada & 2500 & 3000 & ------ & 1200 \\
\hline Castelldans & 720 & $2^{\circ}$ ascenso & Entrada & 5500 & 4500 & 1000 & 1200 \\
\hline Corbins & 1.071 & $2^{\circ}$ ascenso & Ascenso & 5500 & 6500 & 1000 & 1800 \\
\hline
\end{tabular}




\begin{tabular}{|c|c|c|c|c|c|c|c|}
\hline \multirow{2}{*}{ Población } & \multirow{2}{*}{ Habitantes } & \multirow{2}{*}{$\begin{array}{l}\text { Clasificación } \\
\text { Actual }\end{array}$} & \multirow{2}{*}{$\begin{array}{l}\text { Clasificac. } \\
\text { Arreglo }\end{array}$} & \multicolumn{2}{|c|}{ Dotación personal } & \multicolumn{2}{|c|}{ Asignación culto } \\
\hline & & & & Actual & Arreglo & Actual & Arreglo \\
\hline Granja Escarp & 1.210 & $2^{\circ}$ Ascenso & Ascenso & 5500 & 6500 & 1200 & 1800 \\
\hline Granyena & 665 & 1er ascenso & Entrada & 4500 & 4500 & 1000 & 1200 \\
\hline Juncosa & 960 & $2^{\circ}$ ascenso & Ascenso & 5500 & 5500 & 1500 & 1800 \\
\hline Juneda & 2.075 & Término & Ascenso & 7000 & 8000 & 3500 & 2200 \\
\hline Llardecans & 859 & $2^{\circ}$ ascenso & Entrada & 5500 & 5500 & 1000 & 1800 \\
\hline Masalcoreig & 638 & $2^{\circ}$ ascenso & \begin{tabular}{|l|} 
Entrada \\
\end{tabular} & 5500 & 4500 & 1000 & 1200 \\
\hline Montoliu & 319 & Entrada & Entrada & 3300 & 3000 & 1000 & 1200 \\
\hline $\begin{array}{l}\text { Pobla de la } \\
\text { Granadella }\end{array}$ & 504 & Entrada & Entrada & 3300 & 4000 & 900 & 1200 \\
\hline Puiggros & 263 & $2^{\circ}$ ascenso & Entrada & 5500 & 4500 & 1200 & 1200 \\
\hline Roselló & 708 & Término & Entrada & 7000 & 5000 & 3000 & 1200 \\
\hline Sarroca & 506 & 1er ascenso & Entrada & 4500 & 4000 & 1900 & 1200 \\
\hline Serós & 2786 & Término & Ascenso & 7000 & 8000 & 5000 & 2200 \\
\hline Solerás & 724 & Entrada & Entrada & 3300 & 5000 & 900 & 1200 \\
\hline Soses & 874 & $2^{\circ}$ ascenso & Entrada & 5500 & 5500 & 1500 & 1800 \\
\hline Sudanell & 823 & Término & Entrada & 7000 & 5500 & 3000 & 1800 \\
\hline Sunyer & 490 & 1er ascenso & Entrada & 4500 & 3900 & 900 & 1200 \\
\hline Torms & 483 & $2^{\circ}$ ascenso & Entrada & 4400 & 3500 & 1200 & 1200 \\
\hline Torrebeses & 848 & $2^{\circ}$ ascenso & Entrada & 5500 & 5500 & 1000 & 1800 \\
\hline Torrefarrera & 709 & $2^{\circ}$ ascenso & Entrada & 5500 & 4500 & 1900 & 1200 \\
\hline Torregrosa & 1325 & Término & Ascenso & 7000 & 7000 & 1300 & 2000 \\
\hline Torrelameu & 610 & 1er ascenso & Entrada & 3600 & 4500 & 1000 & 1200 \\
\hline Torreserona & 337 & Entrada & Entrada & 3300 & 3000 & 900 & 1200 \\
\hline Torres de Segre & 1900 & Término & Ascenso & 7000 & 7500 & 2000 & 2200 \\
\hline $\begin{array}{l}\text { Vilanova } \\
\text { d'Alpicat }\end{array}$ & 1109 & 1er ascenso & Ascenso & 4500 & 6500 & 900 & 1800 \\
\hline $\begin{array}{l}\text { Vilanova de la } \\
\text { Barca }\end{array}$ & 585 & 1er ascenso & Entrada & 4500 & 4000 & 900 & 1200 \\
\hline $\begin{array}{l}\text { Vilanova del } \\
\text { Segrià }\end{array}$ & 2.522 & $2^{\circ}$ ascenso & Entrada & 4500 & 4000 & 1000 & 1200 \\
\hline TOTAL & 64.928 & --------- & --------- & 278.300 & 297.100 & 84.300 & 90.600 \\
\hline
\end{tabular}

Fuente: elaboración propia a partir de los datos del AMJ, Sección eclesiástica, legajo 3836, expediente número 15.483, Expediente general de arreglo de parroquias, 1857. 
ANEJo 2:

Festejos realizados en Olite al ser conocedores del nombramiento de Pedro Cirilo Úriz como obispo de Lleida:

«Con fecha tres de agosto de mil ochocientos cuarenta y nueve se digno este Señor comunicar desde Tarazona a este Cabildo la plausible noticia de haber sido presentado por S. M. a la silla o mitra de Lérida. Con fecha del siete de junio comunicó su confirmación por Su Santidad en veinte de mayo próximo pasado del año cincuenta; cuyas actas obran en el archivo del Cabildo.; con fecha, por fin, de dieciséis de septiembre lo hizo de haber dispuesto en unión con los demás Señores Obispos celebrar la consagración en su Parroquia de San Pedro. Todas las comunicaciones y sus respuestas obran en el archivo del Cabildo. Llegó el diecinueve de septiembre, día tan deseado por los hijos de Olite. Las campanas desde el último cimbalillo hasta las más graves nos anunciaron la alborada; las puertas y avenidas de la ciudad interceptadas por la afluencia de las gentes de la Ribera; los hijos de Olite apenas se distinguían por la confusión en las casas, calles y plazas, y todos vestidos de gala, y todos con los corazones rebosando en alegría se verificaban unos en adornar las fachadas de las casas, otros en tapizar de flores y yerbas aromáticas las calles por donde había de pasar el consagrado. Toda la plaza estaba cubierta de vasos de diversos colores el frontispicio del primer cuerpo de la torre del Relox; igual decoración tenía el frontispicio de la casa del Ayuntamiento. En el atrio de la Parroquia de San Pedro se abrió una tercera puerta frente de la principal de la iglesia, llamada desde entonces «La Puerta de los Obispos». Sobre ella se formó un magnífico arco. La magnífica portada del templo y la elegante claraboya del coro estaban cubiertas de ramos de variados colores; por entre todo parece como que se elevaba su gigantesca torre, agitando sus pendones y banderas de día y vistiéndose de gala con sus innumerables luces de noche, no queriendo ser menos que la Población, si bien su luminaria parecía un volcán. A las ocho de la mañana salió el Sr. D. Pedro Cirilo Úriz de su casa, y al verlo vestido de obispo un grito tierno de amor a la vez que respetuoso fue el acompañamiento que hubo hasta la iglesia. Iban en la comitiva el consagrante Nuestro Exmo e Ilmo. Señor D. Severo Andriani, Obispo de Pamplona, los Ilmos. Señores D. Miguel José de Irigoyen, Obispo de Zamora y preconizado por Calahorra y don Vicente José Ortiz y Labastida, Obispo de Tarazona. No asistió el padrino don Pedro Labairu, tío del consagrado, pero en su lugar lo hizo el Señor D. Hemeterio Úriz hermano del consagrado. Precediendo las dos corporaciones, eclesiástica y civil y los representantes del cabildo catedral de Tarazona. ¿Qué es lo que se hizo o cuales fueron las ceremonias de la consagración? Todo consta en un folletito impreso a que me remito. Sólo sí diré que a pesar de la afluencia de gente, a pesar de estar llena la iglesia, se conservó el orden y el respeto debido al Santo templo sin que hubiese necesidad de otra fuerza que la que inspiraba tan augusta ceremonia, cosa que llamó la atención a los mismos Señores Obispos, diciendo uno de estos Señores a voz en grito: ¡Bien hijos de Olite, os habéis acreditado de religiosos, que Dios os conserve con tan buenos sentimientos!.

Hubo corrida de novillos, muchos y variados fuegos costeados por ambas corporaciones eclesiástica y municipal, a las que se dignaron asistir los cuatro Señores Obispos y tomaron asiento en el balcón del Ayuntamiento. Desde la casa que habitaba el I. Sr. Don Pedro Cirilo salieron los cuatro subiendo calle arriba hasta la plaza, por toda la calle eran acompañados de un silencio piadoso, para desembocar en la plaza al grito de ¡Viva la Religión! Proferido por ocho mil bocas; el silencio se convirtió en santo entusiasmo. 
¡Oh! Decía el Obispo de la Diócesis: Todavía hay fe en Israel. Ambas corporaciones los acompañamos desde casa a casa del Ayuntamiento y viceversa, habiéndose después repartídose los individuos de las corporaciones para acompañar a los tres Señores Obispos a sus respectivas casas, que fueron: la de don José García y Úriz para el Señor Obispo de Tarazona; la de don Lucas Úriz para el electo de Calahorra y la de don Gabriel vicario de las religiosas para el de Pamplona.

El Imo. Sr. Don Pedro Cirilo Úriz nació en la calle llamada de Medios. Su casa está situada en una de las cuatro esquinas que hay bajando de la plaza, y es la que da al oriente por la calle y al mediodía por la belena. Para la consagración pasó a la casa de sus padres y es la que afronta por oriente a la calle mayor, por el norte a belena llamada de Revillas. Para perpetua memoria firmo. D. Pedro Suescun», Archivo de San Pedro de Olite, Libro 6: bautizos 1843-1861. Consagración del Ilmo. Don Pedro Cirilo Úriz y Labairu, obispo de Lérida.

BIBLIOGRAFÍA

Aubert, Roger. 1974. Historia de la Iglesia. Pío IX y su época, vol. XXIV: Valencia: EDICEP.

Carcel Ortí, Vicente. 1966. «Los boletines oficiales eclesiásticos en España», Hispania Sacra 37.

Carcel Ortí, Vicente. 1975. «El clero durante la revolución de 1868 y la Primera República española», Analecta Sacra Tarraconensia XLVIII: 152-153.

Carcel Ortí, Vicente. 2001. «Los estudios eclesiásticos en Cataluña y la Pontificia Universidad de Tarragona (1897-1934)». XX Siglos 2: 31-40.

Casals Bergés, Quintí. 2001.»Absolutismo y revolución Liberal en Lleida (17151868). La lucha sociopolítica por la toma de la Paeria», La revolución liberal: (Congreso sobre la Revolución liberal española en su diversidad peninsular (e insular) y americana, Madrid, abril de 1999): 67-96.

Casals Bergés, Quintí. 2002. Polítics de Lleida. El poder local i les seves mutacions a través del temps (1716-1868): Lleida: Diputació de Lleida.

Closa Salinas, Francesc. 2002. «Les demarcacions diocesanes i els arranjaments parroquials, instruments per a la reconstrucció dels bisbats: el cas de la diòcesi de Lleida (1800-1905)», Segon Congrés Recerques. Enfrontaments civils: postguerres i reconstruccions: 492-512: Lleida: Servei de Publicacions de la Universitat de Lleida.

Closa Salinas, Francesc. 2003. «El poder eclesiàstic a Lleida (1800-1905): entre l'immobilisme i el regeneracionisme social», Xavier Eritja, Joan Sagués y Maite Solanes (a cura de), Conèixes la teva ciutat...? Lleida vuitcentista. XXIII Campanya, març de 2003: 41-76. Lleida: Ateneu Popular de Ponent.

Closa Salinas, Francesc. 2003. Església i poder a la Lleida del segle XIX. Control i mobilització social: Pedro Cirilo Úriz y Labayru (1850-1861): Lleida: Servei de Publicacions de la Universitat de Lleida. 
Closa Salinas, Francesc. 2004. «L'estada del bisbe Pedro Cirilo Úriz y Labairu a Lleida (1850-1861): poder polític i mobilització católica». Analecta Sacra Tarraconensia 77: $381-412$.

Closa Salinas, Francesc y Lladonosa Vall-llebrera, Manuel. 2009. «El catolicisme lleidatà. Entre liberals, carlins i integristes», Arrels Cristianes. Vol.IV. Temps de llums $i$ obres, temps d'esperança: 61-80: Lleida: Pagès editors.

Cortes, Antonio Luis y Lopez, Miguel Luis. 1996. «Las visitas ad limina y las visitas pastorales como instrumento de control (la diócesis de Granada en la segunda mitad del siglo XVIII)», en Juan Luis Castellanos (ed.), Sociedad, Administración y Poder en la España del Antiguo Régimen: 287-313 Granada: Servicio de Publicaciones de la Universidad de Granada.

Cuenca Toribio, José Manuel. «El pontificado pamplonés de Pedro Cirilo Úriz y Labayru (1862-1870)», Cuadernos de Investigación Histórica 3: 55-124.

Cuenca Toribio, José Manuel. 1969. «El pontificado Pamplonés de D. Pedro Cirilo Úriz y Labayru (1862-1870)», Hispania Sacra XXII: 129-287

Cuenca Toribio, José Manuel. 1976. Sociología de una élite de poder de España e Hispanoamérica Contemporánea: la jerarquía eclesiástica (1789-1965): Córdoba: Escudero.

Cuenca Toribio, José Manuel. 1980. Sociedad y clero en la España del siglo XIX: Córdoba: 166-180 Córdoba: Monte de Piedad y Caja de Ahorros.

Fuentes, Primitivo. 1848. Guía del estado eclesiástico de España y de los dominios de S.M. en América y Asia para el año de 1849, redactada y publicada con real permiso; Madrid: Ministerio de Gracia y Justicia.

Goñi Gaztambide, Jose 1991. Historia de los obispos de Pamplona. Siglo XIX, vol. X: Pamplona: Ediciones Universidad de Navarra.

Ibarra, J. 1953. Biografías de los ilustres navarros del siglo XIX y parte del XX, tomo IV: 376-379 Pamplona.

Jové, Antoni; Lladonosa, Manuel y Vicedo, Enric. 2003. Història de Lleida. El segle XIX: Lleida: Pagès editors.

Madoz, Pascual. 1985. Diccionario geográfico-estadístico-histórico de España: Barcelona: Biblioteca Santa Ana.

Messeguer, José. 1893. Ampliación del arreglo y demarcación de parroquias del Obispado de Lérida por la restauración de San Martín de la Capital, hecha por el Ilustrísimo José Messeguer y Costa, Obispo de Lérida: Lérida: Imprenta Mariana.

Messeguer, José. 1893. Carta pastoral en el que Ilmo O de Lérida anuncia el planteamiento del nuevo plan y demarcación parroquial: Lérida: Imprenta Mariana.

Parramon Doll, Antonio Maria. 1966-1968. «Los boletines eclesiásticos leridanos. Tres publicaciones centenarias», Ilerda XXIX: 299-310. 
Pérez Alhama, Juan. 1967. La iglesia y el estado español: Madrid: Instituto de Estudios Políticos.

Pons Altés, Josep Maria. 1998. El poder polític a Lleida. 1843-1854. Eleccions $i$ pronunciaments: Lleida: La Mañana.

Pons Altés, Josep Maria. 2002. Moderats i progressites a la Lleida del segle XIX: Lleida: Pagès editors.

Pons Altés, Josep Maria. 2005. «Església i política a la Lleida de mitjan segle XIX: reconciliació, legitimació i conflictes». Església, societat i poder a les terres de parla catalana. Actes del IV Congrés de la CCEPC: Barcelona: Institut Ramon Muntaner: 225-238.

Prats, Joaquim. 1988. La Universidad de Cervera en el siglo XVIII: Barcelona: Publicacions Universitat de Barcelona.

Puigvert, Joaquim (ed.). 2003. Les Visites pastorals: dels orígens medievals a l'època contemporània: Girona: CCG edicions.

Reglamento Provisional para los Rdos. Beneficiados o Capellanes asistentes según el Concordato extensivo a los Rdos. Beneficiados laicales al ponerse en planta el arreglo parroquial. Con aprobación real. Con licencia del Señor Obispo, Lérida, 1868.

Revuelta Perez, Manuel. 1984. La Compañía de Jesús en la España contemporánea, T. I: Madrid: Universidad Pontificia Comillas.

Sanchez Carcelén, Antonio. 2005. «La repressió dels eclesiàstics absolutistes lleidatans al Trienni Liberal: el cas del bisbe Renteria», Revista HMiC: història moderna $i$ contemporània 3: 351-372.

Sánchez i Carcelén, Antonio. 2007. «La repercusión del régimen constitucional en la Iglesia de Lleida durante el trienio liberal». Hispania sacra 119, 323-336.

Sánchez i Carcelén, Antonio. 2009. Els defensors de Ferran VII a Lleida (18231833): Lleida: Universitat de Lleida.

Sánchez i Carcelén, Antonio. 2010. «Eclesiásticos catalanes y las Cortes de Cádiz». Anuario de historia de la Iglesia 19: 119-140.

Sánchez i Carcelén, Antonio. 2012. Absolutisme i liberalisme: l'Església de Lleida durant el regne de Ferran VII: Barcelona: Ajuntament de la Pobla de Claramunt.

Tibau Duran, Narciso. 1948. Apuntes biográficos del Excmo. y Rvdmo. P. Salvio Huix Miralpeix, obispo de Lérida: Lérida: Artis Estudios Gráficos.

Úriz, Pedro Cirilo. 1851. Exhortación del Obispo de Lérida a los párrocos y demás eclesiásticos de su Diócesis: Lérida: Imprenta Mariana.

Úriz, Pedro Cirilo. 1856. Prevenciones para el ejercicio de la cura práctica espiritual: Lérida, Imprenta Corominas.

Úriz y Lasaga, Javier. 1856. Carta Pastoral. Prevenciones para el ejercicio de la cura práctica espiritual, que escribió para los párrocos el Excmo. y que reimprime con 
su conocimiento y asenso del Ilmo. Sr Pedro Cirilo Úriz Prelado de Lérida: Lérida: Imprenta Mariana.

Úriz, Pedro Cirilo. 1859. Exhortación Pastoral que el Ilmo Pedro Cirilo Úriz Obispo de Lérida dirige a sus diocesanos con motivo de la alocución pronunciada por S.S. Pío Papa IX en el Consistorio de 26 de setiembre de 1859: Lérida: Imprenta Mariana.

Úriz, Pedro Cirilo. 1859. Exhortación Pastoral que el Ilmo Pedro Cirilo Úriz Obispo de Lérida dirige a sus diocesanos con motivo de la alocución pronunciada por S.S. Pío Papa IX en el Consistorio de 26 de setiembre de 1859: Lérida: Imprenta Mariana.

Úriz, Pedro Cirilo. 1860. Circular del Ilustrísimo Señor Obispo de Lérida Al clero y pueblo de su diócesis del Arcipestrazgo de Ager y Abadiado de la O, comunicándoles la encíclica de su Santidad de 19 de enero último: Lérida: Imprenta Mariana.

Úriz, Pedro Cirilo. 1860. Exhortación Pastoral que el Ilustrísimo Pedro Cirilo Úriz Obispo de Lérida dirige a sus diocesanos con motivo del Empréstito Pontificio: Tarragona: Imprenta Mariana.

Úriz, Pedro Cirilo. 1861. Exhortación Pastoral que el Ilmo Pedro Cirilo Úriz Obispo de Lérida dirige a sus diocesanos con motivo de la alocución pronunciada por S.S. Pío Papa IX en el Consistorio de 30 de setiembre de 1861: Tarragona: Imprenta Mariana.

Úriz, Pedro Cirilo. 1861. Exhortación Pastoral que el Ilustrísimo Pedro Cirilo Úriz Obispo de Lérida dirige a sus diocesanos con motivo de la alocución pronunciada por S.S. Pío Papa IX en el Consistorio de 18 de marzo de 1861: Tarragona: Imprenta Mariana.

Viola, Ramiro. 1983. El Seminario de Lérida conocido y frecuentado por el padre Palau: 35 Roma: Carmelitas Misioneras Teresianas.

Viola, Ramiro. 1984. Historia de la Congregación de Carmelitas Misioneras Teresianas: Roma: Imprenta Monte Carmelo. 